\title{
A Common Substrate for Prefrontal and Hippocampal Inhibition of the Neuroendocrine Stress Response
}

\author{
Jason J. Radley ${ }^{1}$ and Paul E. Sawchenko² \\ ${ }^{1}$ Department of Psychology, University of Iowa, Iowa City, Iowa 52242 and ${ }^{2}$ Laboratory of Neuronal Structure and Function, The Salk Institute for \\ Biological Studies, and The Clayton Medical Research Foundation, La Jolla, California 92037
}

\begin{abstract}
A network of interconnected limbic forebrain cell groups, including the medial prefrontal cortex (mPFC) and hippocampal formation (HF), is known to shape adaptive responses to emotionally stressful experiences, including output of the hypothalamo-pituitary-adrenal (HPA) axis. While disruption of limbic HPA-inhibitory systems is implicated in stress-related psychiatric and systemic illnesses, progress in the field has been hampered by a lack of a systems-level understanding of the organization that provides for this regulation. Using rats, we first localized cell groups afferent to the paraventricular hypothalamic nucleus (PVH) (the initiator of HPA responses to stress) whose engagement following acute $(30 \mathrm{~min}$ ) restraint was diminished by excitotoxin lesions of the ventral subiculum, a component of the HF. This identified a candidate relay for imparting HF influences in a circumscribed portion of the anterior bed nucleus of the stria terminalis (aBST), which we previously identified as a GABAergic relay subserving mPFC inhibition of the stress axis. Anatomical tracing experiments then indicated that extrinsic projections from HF and mPFC converge onto regions of aBST that contain neurons that are both stress sensitive and PVH projecting. Two final experiments provided evidence that (1) HPA-inhibitory influences of mPFC and HF are additive and (2) aBST plays a more prominent inhibitory role than ventral subiculum over stress-induced HPA endpoints. These findings support the view that stress-inhibitory influences of $\mathrm{mPFC}$ and $\mathrm{HF}$ are exerted principally via convergence onto a common relay, as opposed to a serial, parallel, or more complex multisynaptic network.
\end{abstract}

\section{Introduction}

Responding adaptively to stress requires processing information from one or more sensory modalities, including comparing the threat at hand with past experience and affixing an emotional valence to it, and then engaging an appropriate mix and weight of autonomic, neuroendocrine, and behavioral adjustments. Cell groups in the limbic forebrain, notably aspects of the amygdala, hippocampal formation (HF), and medial prefrontal cortex ( $\mathrm{mPFC}$ ) are implicated not only in cognitive/affective responses to stress (e.g., fear, anxiety) (Cullinan et al., 1995, 1996; Li and Sawchenko, 1998; Dayas et al., 2001) but also in endocrine adjustments, by modulating activity of the hypothalamic-pituitaryadrenal (HPA) axis (Sapolsky et al., 1984; Kovács and Makara, 1988; Diorio et al., 1993). Involvement in both contexts may be effected via neuronal and/or hormonal mechanisms, as limbic forebrain structures are major targets of glucocorticoid (GC) mediators of HPA function (Sapolsky et al., 1984; Kovács and Makara, 1988; Diorio et al., 1993).

\footnotetext{
Received Oct. 26, 2010; revised April 27, 2011; accepted April 28, 2011.

Author contributions: J.J.R. and P.E.S. designed research; J.J.R. performed research; J.J.R. analyzed data; J.J.R. and P.E.S. wrote the paper.

This work was supported by National Institutes of Health Grant DK-26741 and was conducted in part by The Clayton Medical Research Foundation. P.E.S. is an Investigator of The Clayton Medical Research Foundation. J.J.R. is supported by a National Alliance for Research on Schizophrenia and Depression Young Investigator award. We also thank Linda Feighery and Belle Wamsley for editorial assistance, and Carlos Arias, Soon Lee, and Joan Vaughan for technical assistance.

Correspondence should be addressed to Dr. Jason J. Radley, Department of Psychology, University of lowa, E232 Seashore Hall, lowa City, IA 52242. E-mail: jason-radley@uiowa.edu.

DOI:10.1523/JNEUROSCI.6040-10.2011

Copyright $\odot 2011$ the authors $\quad 0270-6474 / 11 / 319683-13 \$ 15.00 / 0$
}

Since the recognition that that GC receptor expression is enriched throughout the limbic forebrain, the HF (McEwen et al., 1968), in particular, has received much attention as a region centrally positioned to inhibit emotional stress-induced HPA activation, via GC receptor-mediated negative feedback (Jacobson and Sapolsky, 1991; McEwen, 2001). Importantly, prolonged stress exposure or exogenous GC administration can adversely impact hippocampal structure and function (Sapolsky et al., 1985; Watanabe et al., 1992) associated with dysregulation of the HPA axis (Ottenweller et al., 1989; Herman et al., 1995; Willner, 1997). While these observations have fostered the popular hypothesis that withdrawal of hippocampal HPA-inhibitory influences contributes to the etiology of depression and other stress-related psychopathologies (Carroll et al., 1976; Bremner et al., 1995; Sapolsky, 1996; Sheline et al., 1996), progress has been hampered by the fact that the underlying neural substrates are poorly understood.

The final common pathway for stress-induced HPA axis activation is the paraventricular hypothalamic nucleus $(\mathrm{PVH})$, which houses corticotropin-releasing factor (CRF)-expressing neurons that regulate GC secretion (Antoni, 1986). Stressinhibitory influences of HF are not imposed by direct innervation of PVH; instead, relevant extrinsic projections arise predominantly from the ventral subiculum (vSUB), using the excitatory neurotransmitter, glutamate (Swanson and Cowan, 1977; Walaas and Fonnum, 1980; Cullinan et al., 1993). These may target one or more GABAergic intermediaries [bed nucleus of the stria terminalis (BST); medial preoptic area; hypothalamic regions] that may be capable of imparting HPA-inhibitory influences emanat- 
ing from vSUB (Swanson and Cowan, 1977; Cullinan et al., 1993; Herman et al., 2003), though others have posited an involvement of complex, multisynaptic pathways for hippocampal modulation of the stress axis (Feldman and Conforti, 1981; Feldman et al., 1987). The present study sought to elucidate the neural systems that underlie this regulation.

An initial experiment identified a candidate for imparting HF influences in the same aspects of the anterior BST (aBST) that we previously identified as comprising a GABAergic relay subserving mPFC inhibition of the stress axis (Radley et al., 2009). Subsequent anatomical and functional studies support the contention that stress-inhibitory influences of the MPFC and vSUB converge onto a common relay in aBST.

\section{Materials and Methods}

Animals and treatments. Adult male Sprague Dawley albino rats, maintained under standard laboratory conditions, were used in all experiments. All experimental protocols were approved by the Institutional Animal Care and Use Committee of The Salk Institute. Restraint stress was performed in the morning (9:00 A.M.) in plastic restrainers (Braintree Scientific) for $30 \mathrm{~min}$. Controls were handled comparably but were not restrained. All animals remained in their home cages during and after restraint until the prescribed time of perfusion for histology, $2 \mathrm{~h}$ after the termination of restraint.

Surgeries. Axon-sparing excitotoxin lesions of vSUB were produced via bilateral pressure ejection of ibotenic acid $(10 \mathrm{mg} / \mathrm{ml}$; Sigma-Aldrich) in sterile saline. Injections were placed via pressure ejection (World Precision Instruments) through micropipettes (10-20 $\mu \mathrm{m}$ inner diameter) to deliver $120-150 \mathrm{nl} /$ side at the following stereotaxic coordinates, with the skull flat between bregma and lambda: anteroposterior, $-5.50 \mathrm{~mm}$; mediolateral, $\pm 4.45 \mathrm{~mm}$; dorsoventral, $-7.00 \mathrm{~mm}$ from dura. The extent of damage was estimated by reconstruction from Nissl preparations (see Figs. 1, 2). In a separate experiment, unilateral excitotoxin lesions were made in either vSUB, $\mathrm{mPFC}$, or in both structures on the same side of the brain. Excitotoxin lesions of mPFC were centered in the prelimbic area (PL), as previously described (Radley et al., 2006, 2009), as this region is the principal cortical subfield within $\mathrm{mPFC}$ responsible for imparting HPA-inhibitory influences during emotional stress. In shamlesioned animals, a burr hole was drilled in the skull and dura was pierced in the location dorsal to lesion placements.

For retrograde labeling of PVH-projecting neurons, unilateral pressure injections of 2\% Fluoro-Gold (FG) (Fluorochrome) (Schmued and Fallon, 1986) were made into PVH in volumes of 30-60 nl (anteroposterior, $-1.30 \mathrm{~mm}$; mediolateral, $+0.40 \mathrm{~mm}$; dorsoventral, $-7.2 \mathrm{~mm}$ from dura). Tracer placement and size and the quality of retrograde labeling following deposits into PVH were verified by comparison with previous experiments using iontophoretic injections into the same region (Radley et al., 2009). We and others have previously noted that discretely placed anterograde tracer (PHA-L) injections to the dorsomedial and fusiform aBST labels projections that preferentially innervate the parvicellular PVH (Dong et al., 2001; Dong and Swanson, 2006; Radley et al., 2009).

Anterograde tracing experiments involved one or more of the following (see Results): unilateral pressure ejection of $10 \%$ biotinylated dextran amine (BDA) (Sigma-Aldrich) into PL (anteroposterior, $-2.90 \mathrm{~mm}$; mediolateral, $\pm 0.75 \mathrm{~mm}$; dorsoventral, $-3.50 \mathrm{~mm}$ from dura); unilateral pressure ejection of $10 \%$ BDA into anterior BST (centered within dorsomedial and fusiform subnuclei; anteroposterior, $-0.25 \mathrm{~mm}$; mediolateral, $+1.20 \mathrm{~mm}$; dorsoventral, $-7.20 \mathrm{~mm}$ from dura); unilateral iontophoretic injection of $10 \%$ Fluoro-Ruby (FR) (Invitrogen) into vSUB.

To selectively ablate GABAergic neurons in aBST, anti-GAT-1saporin (a conjugate of the ribosomal toxin, saporin, with a rabbit polyclonal antibody that recognizes the an extracellular domain of the GABA transporter-1; Advanced Targeting Systems) was microinjected bilaterally (Radley et al., 2009). A stock solution $(1.9 \mathrm{mg} / \mathrm{ml})$ was diluted $1: 2$ in artificial CSF (aCSF) at $\mathrm{pH}$ 7.4. Injections were placed via micropipettes
(10-20 $\mu \mathrm{m}$, inner diameter) using pressure ejection (World Precision Instruments) to deliver $120 \mathrm{nl}$ per side. Control lesions involved either injecting saporin conjugated to IgG, or the aCSF vehicle. The extent and specificity of damage was estimated by reconstruction from material hybridized for mRNAs encoding the $67 \mathrm{kDa}$ isoform of the GABAsynthetic enzyme, glutamic acid decarboxylase (GAD67), and CRF (Radley et al., 2009).

Histology and tissue processing. Rats were anesthetized with chloral hydrate $(350 \mathrm{mg} / \mathrm{kg}$, i.p.) and perfused via the ascending aorta with 100 $\mathrm{ml}$ of $0.9 \%$ saline followed by $900 \mathrm{ml}$ of ice-cold $4 \%$ paraformaldehyde in $0.1 \mathrm{~m}$ borate buffer, $\mathrm{pH} 9.5$, at a flow rate of $55 \mathrm{ml} / \mathrm{min}$. The brains were removed, postfixed for $3 \mathrm{~h}$, and cryoprotected in $20 \%$ sucrose in $0.1 \mathrm{M}$ phosphate buffer overnight at $4^{\circ} \mathrm{C}$. Five one-in-five series of $30-\mu \mathrm{m}$ thick frozen coronal sections through the entire brain were cut and collected in cryoprotectant solution and stored at $-20^{\circ} \mathrm{C}$ until processing.

Hybridization histochemistry. Techniques for probe synthesis, hybridization, and autoradiographic localization of mRNA signal were adapted from the study by Simmons et al. (1989). In situ hybridization was performed using ${ }^{35} \mathrm{~S}$-labeled sense (control) and antisense cRNA probes labeled to similar specific activities encoding CRF mRNA (1.2 kb; Dr. K. Mayo, Northwestern University, Evanston, IL), and arginine vasopressin (AVP) heteronuclear RNA (hnRNA) (700 bp fragment from intron I of the rat vasopressin gene; Dr. T. Sherman, University of Pittsburgh, Pittsburgh, PA). Sections were mounted onto poly-L-lysine-coated slides and dried under vacuum overnight. They were postfixed with $10 \%$ paraformaldehyde for $30 \mathrm{~min}$ at room temperature, digested with $10 \mu \mathrm{g} / \mathrm{ml}$ proteinase $\mathrm{K}$ for $15 \mathrm{~min}$ at $37^{\circ} \mathrm{C}$, and acetylated for $10 \mathrm{~min}$. Probes were labeled to specific activities of $1-3 \times 10^{9} \mathrm{dpm} / \mu \mathrm{g}$ and applied to the slides at concentrations of $\sim 10^{7} \mathrm{cpm} / \mathrm{ml}$, overnight at $56^{\circ} \mathrm{C}$ in a solution containing 50\% formamide, $0.3 \mathrm{M} \mathrm{NaCl}, 10 \mathrm{~mm}$ Tris, $1 \mathrm{~mm}$ EDTA, $0.05 \%$ tRNA, $10 \mathrm{~mm}$ dithiothreitol, $1 \times$ Denhardt's solution, and $10 \%$ dextran sulfate, after which they were treated with $20 \mu \mathrm{g} / \mathrm{ml}$ ribonuclease A for 30 $\min$ at $37^{\circ} \mathrm{C}$ and washed in $15 \mathrm{~mm} \mathrm{NaCl} / 1.5 \mathrm{~mm}$ sodium citrate with $50 \%$ formamide at $70^{\circ} \mathrm{C}$. Slides were then dehydrated and exposed to $\mathrm{x}$-ray films (Kodak Biomax MR; Eastman Kodak) for $18 \mathrm{~h}$. They were coated with Kodak NTB-2 liquid emulsion and exposed at $4^{\circ} \mathrm{C}$ for $10-14 \mathrm{~d}$, as determined by the strength of signal on film. Slides were developed with Kodak D-19 and fixed with Kodak rapid fixer, and lightly counterstained with thionin.

Immunohistochemistry. Localization of Fos protein and other antigens was performed on free-floating sections by using an avidin-biotin peroxidase protocol (Sawchenko et al., 1990). Fos immunolocalization was performed using a primary antiserum raised against a fragment of rat Fos protein (residues 4-17), synthesized by J. Rivier (The Salk Institute, La Jolla, CA) and previously characterized (Radley et al., 2008). Endogenous peroxidase was neutralized by treating tissue for $10 \mathrm{~min}$ with $0.3 \%$ hydrogen peroxide, and sections were incubated with primary antiserum at $4^{\circ} \mathrm{C}$ for $48 \mathrm{~h}$ in PBS containing $0.3 \%$ Triton X-100 and 3\% blocking serum. The primary antiserum was localized using Vectastain Elite (Vector Laboratories) reagents, and the reaction product was developed using a nickel-enhanced glucose oxidase method (Shu et al., 1988). Dual immunoperoxidase labeling for Fos and FG immunoreactivity was performed by sequentially localizing the antiserum against Fos using a nickel-enhanced diaminobenzidine method (black nuclear reaction product), as above, and then a FG antiserum (Chang et al., 1990), without nickel enhancement (brown cytoplasmic product). Specificity of the Fos antiserum was evaluated by direct colabeling for c-fos mRNA over a range of challenge conditions (data not shown). In addition, specific staining in experimental and control tissue was abolished by preadsorbing the antiserum overnight at $4^{\circ} \mathrm{C}$ with $50 \mu \mathrm{m}$ of the synthetic peptide immunogen.

In tracing experiments involving BDA, some series of sections were processed using the avidin-biotin peroxidase procedure as described above, For fluorescence labeling of BDA, sections were incubated overnight in the streptavidin-fluorophore conjugate, Alexa 488 (Invitrogen), at a concentration of $2 \mu \mathrm{g} / \mathrm{ml}$. In instances in which fluorescence immunolocalization of Fos was desired (i.e., in conjunction with tracers bearing native fluorescence or BDA fluorescence labeling), sections were 
incubated overnight in a goat anti-rabbit secondary antibody conjugated with Alexa 647 (Invitrogen) at a concentration of $4 \mu \mathrm{g} / \mathrm{ml}$.

Data analysis. Stereological methods were used to quantify the number of Fos-immunoreactive neurons. These analyses were performed using a computer-assisted morphometry system consisting of a photomicroscope equipped with an $X Y Z$ computer-controlled motorized stage, MicroFire camera (Optronics), Gateway microcomputer, and StereoInvestigator morphometry and stereology software (MBF Biosciences). For each analysis, boundaries defining the regions of interest were drawn at $25 \times$ using an adjacent series of Nissl-stained sections. In regions identified as PVH projecting (i.e., retrogradely labeled following FG injections in PVH), labeled cells were used as a guide to further aid the delineation of anatomical boundaries. Analyses of Fos-immunoreactive cells were performed on every fifth section, avoiding cells in the outermost plane of focus. Counts were then multiplied by 5 to estimate the total number of labeled neurons in the defined region of interest. Volume estimates from cross-sectional area measurements were obtained using the Cavalieri method to probe for possible treatment effects on $\mathrm{PVH}$ volume, but no reliable effects were observed.

Semiquantitative densitometric analysis of relative levels of CRF mRNA was performed on emulsion-coated slides using ImageJ software. The optical densities of hybridization signals were determined under dark-field illumination at $10 \times$ magnification. The hypophysiotropic PVH (i.e., dorsal medial parvicellular subdivision) was defined from Nissl staining pattern (Swanson and Kuypers, 1980) and aligned with corresponding dark-field images of hybridized sections by redirected sampling. Optical density readings, corrected for background, were taken at regular, $150 \mu \mathrm{m}$ intervals, and average values were determined through the extent of this cell group for each animal. Images from CRF mRNA densitometry were collected using a Hamamatsu Orca CCD camera under the control of OpenLab software (version 3.1.5). Images collected from each analysis were exported first to Adobe PhotoShop (version 7) for adjustments to optimize/balance contrast and brightness, and then to Canvas (version 8) for assembly and labeling.

Analysis of AVP hnRNA expression in the PVH was performed by counting the number of small-diameter nuclei (i.e., $<10 \mu \mathrm{m}$ ) in the medial parvicellular subdivision that were overlain by reduced silver grains (more than three grains per nuclei) (Kovács et al., 2000). Scattered ectopic magnocellular neurosecretory neurons within the parvicellular division of PVH were recognized on Nissl-counterstained material under bright-field illumination and were excluded from the analysis on the basis of nuclear diameter.

Analysis of material containing multiple fluorescent markers was examined using a Leica SP2 confocal laser-scanning microscope, and markers were scanned sequentially, using excitation/emission settings for FG and Alexa dyes that were non-overlapping. Digital reconstructions of multiple fluorescence labeling for tracer and/or Fos-immunolabeled material were acquired using a $63 \times$ oil objective (NA 1.4) with a zoom of $2 \times$, in $0.75 \mu \mathrm{m} z$-steps throughout the entire extent of $30 \mu \mathrm{m}$ sections. The criterion for asserting colocalization of Fos within retrogradely labeled neurons required that Fos-labeled nuclei be ensconced within FGlabeled perikarya within a single $z$-plane. Analyses of potential synaptic contacts involved determination of appositions (i.e., defined by the absence of unlabeled pixels between anterogradely labeled axonal and retrogradely labeled somatic/dendritic elements by examining confocal images within a single optical sections throughout each stack).

Statistics. Grouped data from the immunoperoxidase and hybridization histochemical analyses ( $n=4-5$ per group) were compared using Student's $t$ test when two groups were compared (sham plus stress, lesion plus stress); a one-way ANOVA for lesion and treatment (sham plus stress, mPFC lesion plus stress, vSUB lesion plus stress, double lesion plus stress) status followed by post hoc pairwise comparisons using a Bonferroni correction. Data are expressed as mean + SEM.

\section{Results}

\section{vSUB lesion placements}

The placement and extent of vSUB lesions were evaluated (Fig. $1 A$ ) with reference to its established cytoarchitectonic features (Rose, 1929; Lorente de Nó, 1934). Based on preliminary studies involving dye injections, single injections of relatively small volumes of ibotenic acid (150 nl) were used to provide a balance between maximally ablating vSUB, while sparing adjacent cortical structures. Nonetheless, these injections typically spared the most caudal portions of vSUB, while spread of the lesion was typically observed in the most ventral portion of CA1, presubiculum, parasubiculum, and deep layers of the entorhinal cortex (Fig. 1A).

\section{Effects of vSUB lesions on central indices of stress-induced HPA activation}

We initially surveyed the effects of vSUB lesions on central indices of HPA activation at $2 \mathrm{~h}$ after a single $30 \mathrm{~min}$ exposure to restraint stress, a time point at which induced Fos protein expression is maximal in the hypothalamus and basal forebrain, and which is also sufficient for observing acute stress-induced alterations in CRF mRNA in the PVH (Viau and Sawchenko, 2002). Relative to sham-operated controls, vSUB-lesioned rats subjected to acute restraint displayed a nearly twofold increase (94\%; $p<0.05)$ in the number of Fos-labeled cells in PVH, which were concentrated in the CRF-rich hypophysiotropic zone [medial parvicellular subdivision (mpd)] (Fig. $1 B-D)(N=5$ per group). Stress-induced expression of CRF mRNA in PVH was also enhanced (by $22 \% ; p<0.05$ ) following vSUB lesions (Fig. $1 E-G$ ). These findings are in line with previous work demonstrating that vSUB lesions augment emotional stress-induced PVH/HPA activation (Herman et al., 1995, 1998).

While CRF is the principal ACTH secretagogue required for HPA activation and imparts a stimulatory tone on the axis (Rivier et al., 1982), AVP can be situationally expressed in the same population of hypophysiotropic PVH neurons and is capable of acting as a cosecretagogue by potentiating the actions of CRF on ACTH release during stress (Rivier and Vale, 1983; Plotsky, 1991). Basal levels of expression of AVP hnRNA in PVH parvicellular neurons are low to undetectable but can be upregulated through at least 1.5-2 h after stress (Priou et al., 1993; Kovács and Sawchenko, 1996; Ma et al., 1997). Thus, we explored the possibility that vSUB lesions may enhance stress-induced transcriptional activation of AVP in the parvicellular PVH at $2 \mathrm{~h}$ after restraint. Following acute restraint exposure, vSUB lesions resulted in a $61 \%$ increase in the number of parvicellular neurons in PVH that displayed AVP hnRNA signals, compared with shamlesioned animals $(p<0.05)$ (Fig. $1 H-J)$. By contrast, no significant between-group differences were observed in levels of hybridizable AVP hnRNA throughout the magnocellular division of PVH (data not shown), consistent with previous reports that AVP transcription in these neurons is unresponsive to emotional stress (Herman et al., 1995).

It should be noted that the foregoing design did not include unstressed control groups, as our previous work has verified that stress produces significant increases in PVH indices of HPA activation (Radley et al., 2006, 2009). Moreover, others have reported a failure of vSUB lesions to reliably alter basal indices of HPA activation (Herman et al., 1998; Herman and Mueller, 2006).

\section{Effects of vSUB lesions on stress-induced activation of GABAergic PVH-projecting cell groups}

vSUB has been previously identified as a, if not the, major source of extrinsic HPA-inhibitory projections emanating from the HF (Herman et al., 1998; Herman and Mueller, 2006). The fact that vSUB does not provide substantial direct input to $\mathrm{PVH}$, proper, indicates that its influences are relayed by one or more interposed cell group(s) (Cullinan et al., 1993). Instead, the extrinsic projec- 

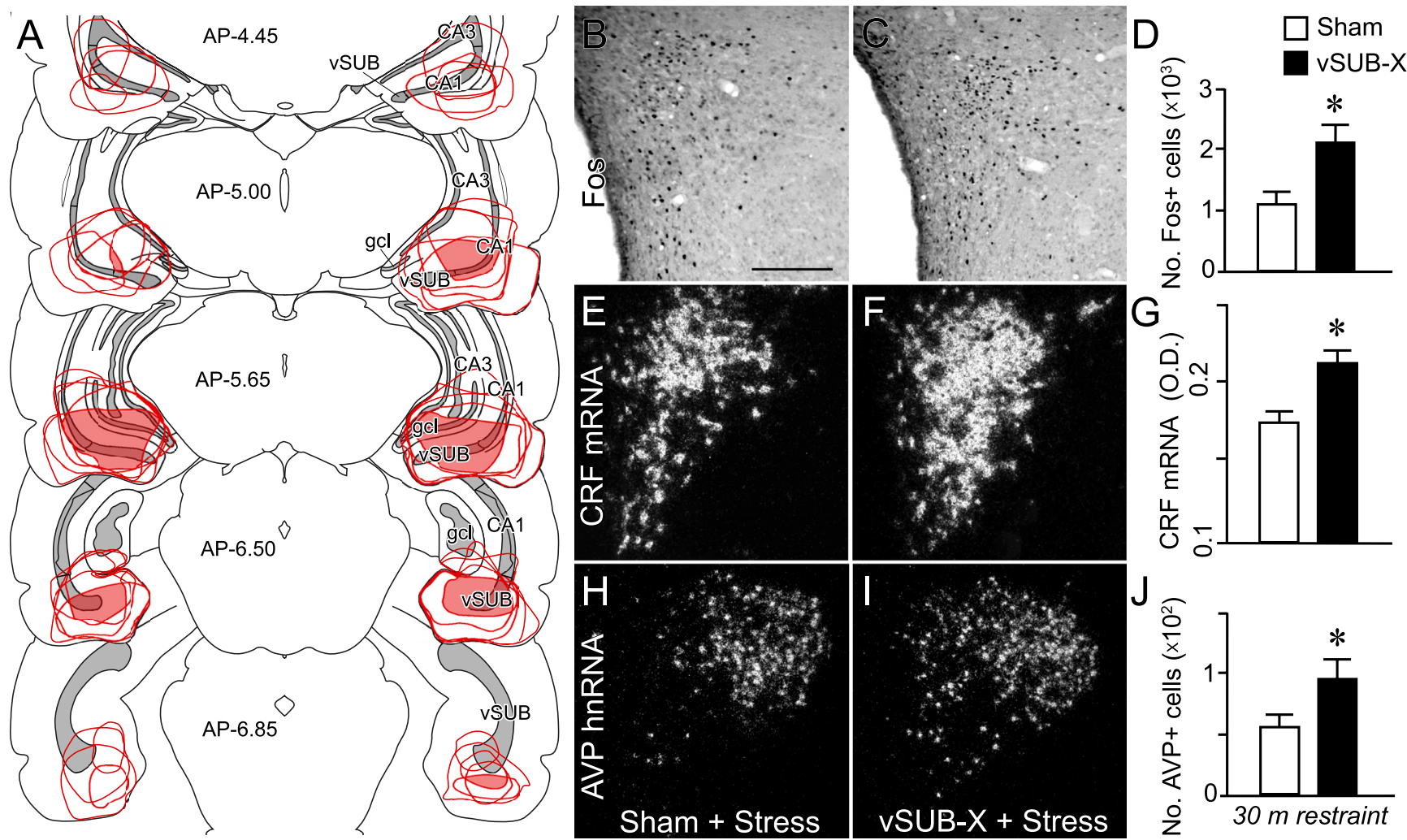

Figure 1. Bilateral injections of ibotenic acid centered in vSUB enhance restraint-induced central indices of HPA activation. $A$, Reconstruction of ibotenic acid lesion placements in vSUB. The solid red areas represent the region of damage common to all members of each group, and outlines show the extent of individual lesions, as defined by the absence of Niss-stained neurons in sham-lesioned animals. Cell loss was most prominent in the anterior portions of vSUB and spread into adjoining ventral aspects of hippocampus, proper. Atlas plates are adapted from Swanson (1992); distance in millimeters relative to bregma is indicated. CA1, CA1 field; CA3, CA3 field; gcl, granule cell layer, dentate gyrus; vSUB, ventral subiculum. Bright-field and dark-field photomicrographs illustrate restraint-induced upregulation of Fos $(\boldsymbol{B}, \boldsymbol{C}), \mathrm{CRF}$ mRNA $(\boldsymbol{E}, \boldsymbol{F})$, and AVP hnRNA $(\boldsymbol{H}, \boldsymbol{I})$ expression in the PVH of animals bearing excitotoxin lesions of vSUB, relative to sham controls. Histograms $(\boldsymbol{D}, \boldsymbol{G}, \boldsymbol{J})$ show corresponding mean + SEM for number of Fos-immunoreactive (-ir) neurons (top), relative levels of (RF mRNA (middle), and AVP hnRNA-labeled parvicellular neurons (bottom) in PVH in treatment groups. ${ }^{*} p<0.05$, differs significantly from sham-lesioned controls. $n=5$ per group. Scale bars: $150 \mu \mathrm{m}$ (applies to all).

tions from vSUB implicated in HPA axis modulation distribute from the extracommissural pathway of the medial corticohypothalamic tract throughout the basal forebrain and hypothalamus (Sesack et al., 1989; Hurley et al., 1991), including to regions that house GABAergic neurons that do directly innervate PVH (Cullinan et al., 1993; Roland and Sawchenko, 1993). Therefore, we sought to determine which GABAergic cell groups might serve to relay stress-inhibitory vSUB influences. Retrograde tracer (FG) was injected into PVH in the same groups of animals that received bilateral excitotoxin or sham lesions of vSUB (as described above; $N=5$ per group), and PVH-afferent cell groups were assayed for lesion-induced reductions in sensitivity to acute restraint. Tracer injections were aimed at the medial parvicellular part of the PVH (Fig. 2), and only animals that included appropriately centered tracer injections with minimal involvement of potentially confounding cell groups were included in the analyses (see Materials and Methods). Dual immunostaining was performed for FG and Fos protein expression in sham- and vSUB-lesioned animals $2 \mathrm{~h}$ after the termination of restraint. Sham-lesioned rats displayed colocalization of Fos and transported tracer predominantly in six distinct regions of the hypothalamus, including the medial preoptic area, anterior hypothalamic area, perifornical area, peri-supraoptic region, dorsomedial and ventromedial hypothalamic nuclei, and several subnuclei of aBST (Table 1). We and others have previously identified these regions as housing stress-sensitive PVH afferents (Cullinan et al., 1996; Radley et al., 2009). Of these, only the aBST [comprising the fusiform, dorsomedial, and subcommissural subnuclei from Dong et al. (2001)] exhibited a significant decrement (by 36\%) in the number of cells labeled concurrently for Fos and tracer in acutely stressed rats bearing vSUB lesions, compared with sham-lesioned animals $(p=0.01)$ (Fig. 3). This occurred despite the lack of a lesion effect on overall stress-induced Fos expression in aBST, and the lack of between-group differences in the number of retrogradely labeled cells in this region (Fig. $3 B, C, F$ ). Further analyses involving combined histochemical localization of Fos protein and mRNA encoding the 65 and 67 $\mathrm{kDa}$ isoforms of glutamate decarboxylase (GAD65/67) (markers of GABAergic neurons) also revealed a significant decrease only in aBST (by $32 \% ; p<0.05$ ) (Fig. $3 D-F$ ). The degree of FG colocalization with GAD65/67 mRNA did not differ between groups, with the vast majority (86\%) of PVH-projecting aBST neurons exhibiting the GABAergic phenotype (Fig. 4). These results support previous indications that GABAergic neurons in aBST are centrally involved in imparting limbic inhibitory influences on acute restraint-induced HPA axis activation (Radley et al., 2009).

\section{Anatomical support for aBST as a relay of vSUB influences on PVH}

Neuroanatomical tracing experiments were performed to evaluate the possibility that HF influences on stress-induced HPA activation may be mediated via a vSUB $\rightarrow$ aBST (GABA) $\rightarrow$ PVH pathway. Pressure injections of the anterograde tracer, BDA, were placed into vSUB alone $(n=4)$, or in combination with FG 


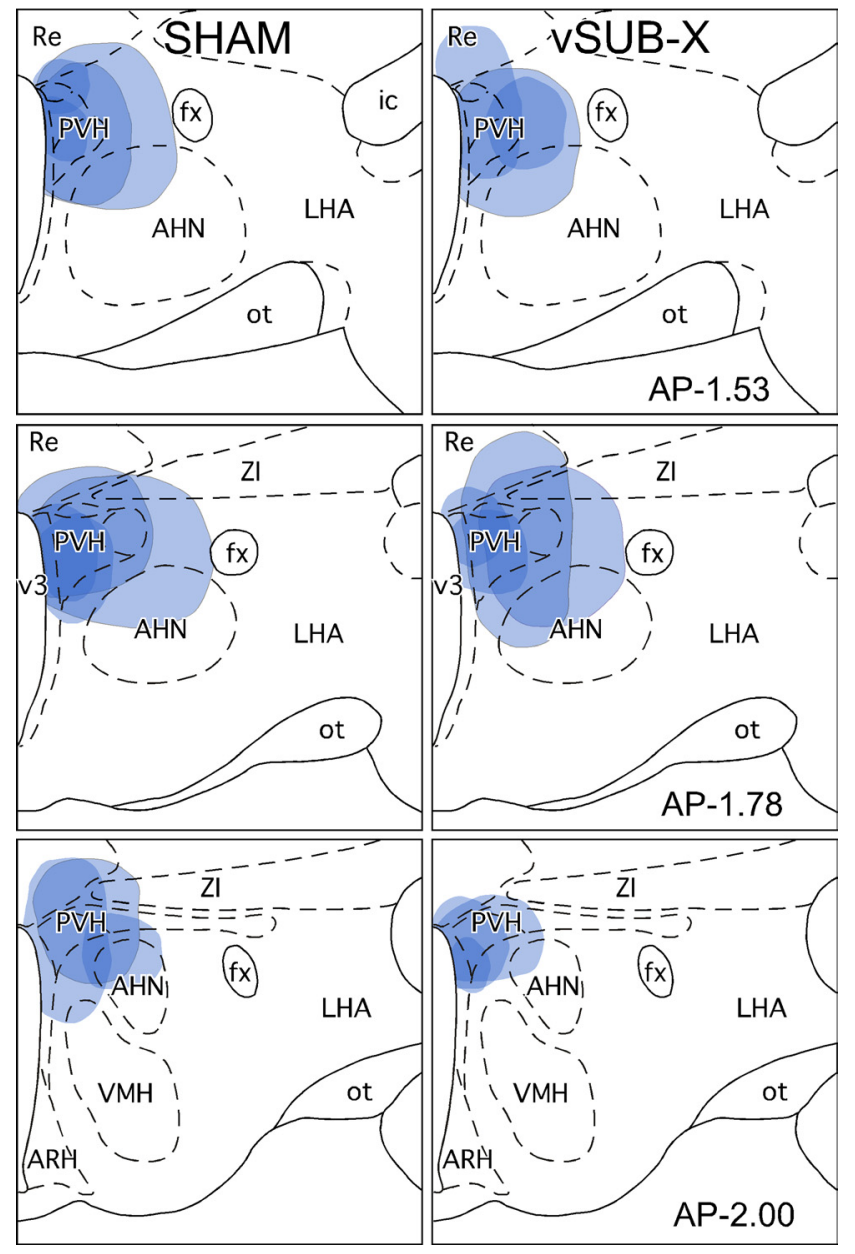

Figure 2. Reconstructions of FG tracer injection placements in PVH in sham- (left) and vSUBlesioned (right) rats. More darkly shaded regions indicate areas where tracer injections overlap. Atlas plates are adapted from Swanson (1992); distance in millimeters relative to bregma is indicated. AHN, Anterior hypothalamic nucleus; ARH, arcuate nucleus hypothalamus; fx, fornix; ic, internal capsule; LHA, lateral hypothalamic nucleus; MeA, medial nucleus amygdala; ot, optic tract; Re, nucleus reunions; SI, substantia innominata; V3, third ventricle; VMH, ventromedial nucleus hypothalamus; Zl, zona incerta.

Table 1. Effect of vSUB lesions on functional activation in PVH-projecting cell groups following acute restraint stress

\begin{tabular}{llc}
\hline & \multicolumn{2}{l}{ No. Fos- plus FG-labeled cells } \\
\cline { 2 - 3 } PVH-projecting cell groups & Sham & vSUB lesion \\
\hline Vicinity of PVH & & \\
$\quad$ Anterior hypothalamic area & $73 \pm 23$ & $78 \pm 30$ \\
$\quad$ Anterior PVH & $23 \pm 5$ & $8 \pm 5$ \\
$\quad$ Peri-supraoptic area & $53 \pm 16$ & $58 \pm 13$ \\
$\quad$ Perifornical area & $30 \pm 6$ & $40 \pm 12$ \\
$\quad$ Zona incerta & $63 \pm 8$ & $60 \pm 14$ \\
Other regions & & \\
$\quad$ Bed nucleus of the stria terminalis, anterior division & $130 \pm 14$ & $83 \pm 10$ \\
$\quad$ Dorsomedial hypothalamus & $110 \pm 29$ & $98 \pm 10^{*}$ \\
$\quad$ Medial preoptic area & $112 \pm 31$ & $173 \pm 23$ \\
\hline
\end{tabular}

Values represent mean \pm SEM for counts made within each region. Asterisk indicates significance $\left({ }^{*} p<0.05\right)$.

injections in PVH $(n=6)$. Histochemical visualization of transported BDA revealed a moderately dense array of labeled fibers and varicosities throughout aBST subdivisions implicated in vSUB modulation of HPA output, most notably in the dorsomedial, dorsolateral, and magnocellular nuclei. Less dense terminal fields were identified in the anteroventral and anterolateral divi-
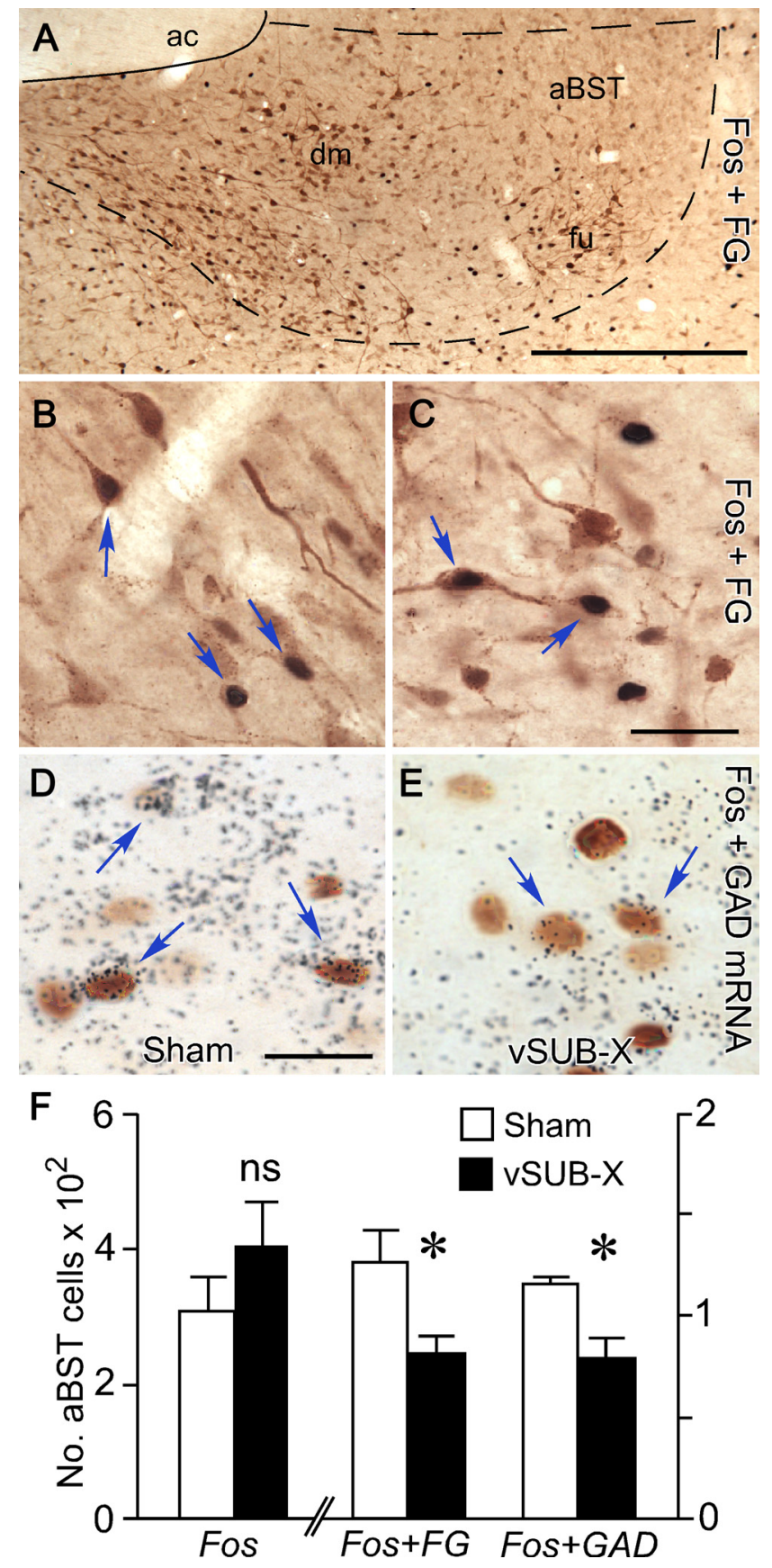

Figure 3. Restraint-induced activational responses of PVH-projecting GABAergic cell groups in aBST and their diminution in animals bearing excitotoxin lesions of vSUB. $\boldsymbol{A}$, Bright-field photomicrographs showing stress-induced Fos immunoreactivity (black nuclei) and FluoroGold (brown cytoplasm) in aBST. Retrogradely labeled cells are concentrated in fusiform (fu) and dorsomedial (dm) subnuclei of aBST following tracer injections centered in the PVH. $\boldsymbol{B}, \boldsymbol{C}$, Following restraint stress, cells doubly labeled for Fos and Fluoro-Gold (arrows) are more abundant in sham-lesioned than vSUB-lesioned animals. $\boldsymbol{D}, \boldsymbol{E}$, Concurrent labeling for Fos (brown) with GAD67 mRNA (black grains) reveals comparable increases in doubly labeled cells (arrows) in the sham- compared with vSUB-lesioned group following restraint stress. $F$, Mean + SEM number of neurons labeled for Fos, colabeled for Fos and Fluoro-Gold, and for Fos and GAD67 mRNA in aBST in treatment groups. Lesions reliably diminished stress-induced activation of PVH-projecting and GABAergic neurons in aBST. ${ }^{*} p<0.05$, differs significantly from shamlesioned stress animals. $n=4-5$ per group. Scale bars: $A, 250 \mu \mathrm{m} ; \boldsymbol{B}, \boldsymbol{C}, 50 \mu \mathrm{m} ; \boldsymbol{D}, \boldsymbol{E}, 20 \mu \mathrm{m}$.

sions, and the fusiform and subcommissural subnuclei of aBST. It is noteworthy that, while vSUB issues massive projections to the anterior and ventromedial hypothalamic nuclei, the PVH receives scant, if any, direct input (Fig. $5 A-C$ ). In animals receiv- 

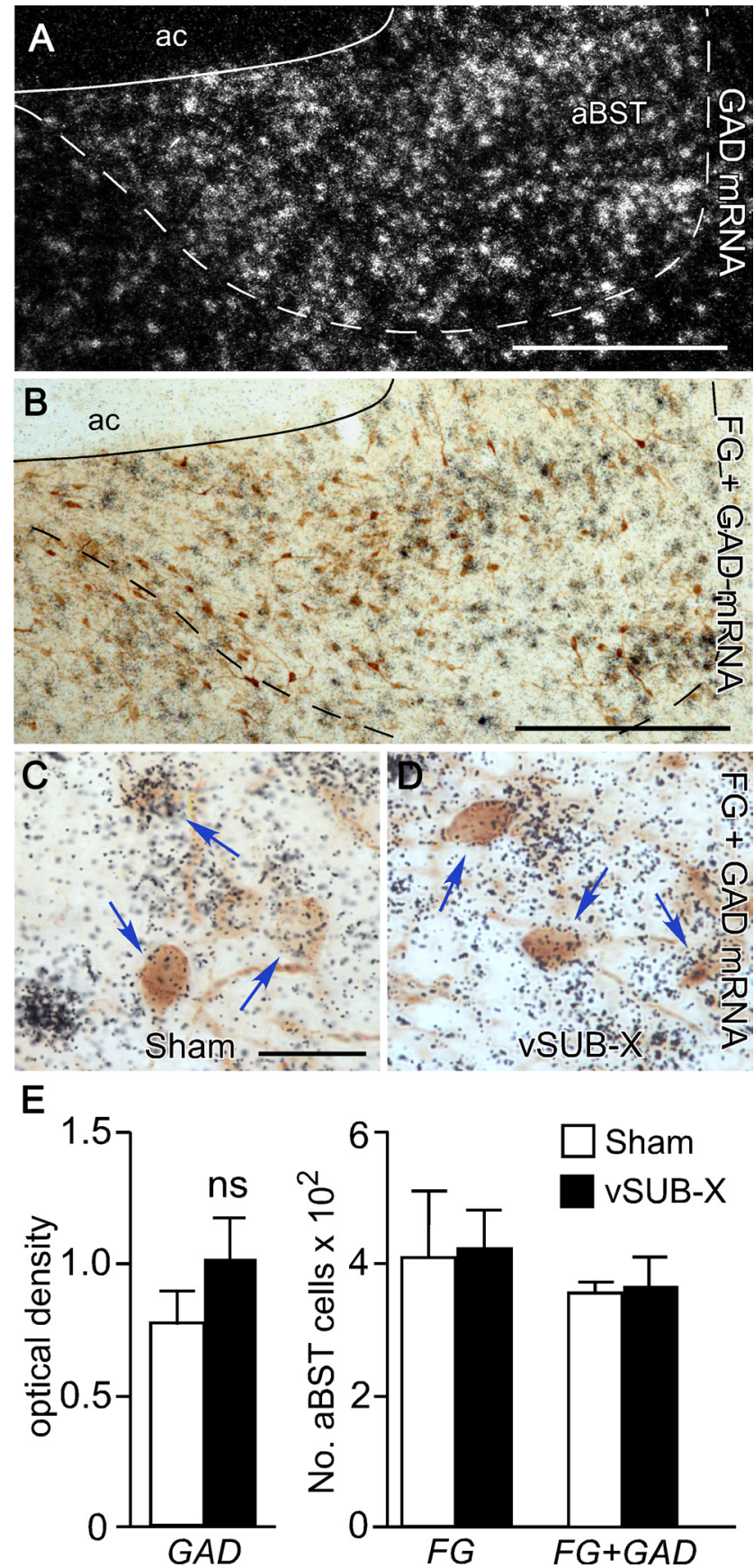

Figure 4. PVH-projecting neurons in aBST are predominantly GABAergic. A, Lowmagnification dark-field photomicrograph of GAD67 mRNA in aBST. $\boldsymbol{B}-\boldsymbol{D}$, Photomicrographs of sections through aBST prepared for dual localization of GAD67 mRNA with immunoperoxidase labeling for $\mathrm{FG}$, following tracer injections in PVH, show numerous instances of PVH-projecting neurons displaying a GABAergic phenotype (arrows). $\boldsymbol{E}$, Histograms showing mean + SEM for relative expression levels of GAD67 mRNA, neurons labeled with FG, and for FG and GAD67 mRNA in aBST in treatment groups; vSUB lesions did not reliably affect these measures. $n=4$ per group. Scale bars: $A, B, 250 \mu \mathrm{m} ; C, D, 20 \mu \mathrm{m}$.

ing dual tracer injections, confocal laser-scanning microscope analysis revealed frequent instances of close appositions between labeled axonal elements from vSUB and PVH-projecting neurons (Fig. $5 D-G$ ).

\section{Convergence of vSUB and PL projections on aBST}

We previously identified a subset of PVH-projecting neurons in aBST that comprise a GABAergic relay for imposing mPFC (no- tably the PL) inhibition of the stress axis (Radley et al., 2009). This raises the possibility that $\mathrm{HF}$ and $\mathrm{mPFC}$ influences may converge onto a common population of aBST neurons, though in view of the extensive interconnectivity among limbic forebrain structures, a serial processing arrangement cannot be discounted. Therefore, we sought to determine whether these cortical limbic influences are organized in a serial or convergent manner.

We first evaluated a possible anatomical basis for convergence of projections from vSUB and PL onto PVH-projecting neurons in aBST. Pressure injections of the anterograde tracers BDA and FR were placed in PL and $\mathrm{vSUB}$, respectively, in combination with retrograde tracer injection of FG in PVH $(n=12)$ (Fig. $6 \mathrm{~A}-\mathrm{C}$ ). Analysis of overlap of terminal fields emanating from PL and vSUB revealed extensive intermingling throughout aBST, notably among $\mathrm{PVH}$-projecting neurons clustered within the fusiform and dorsomedial nuclei (Fig. 6D). Nonetheless, some subtle differences were noted between PL and vSUB innervation patterns, consistent with their different origins within the limbic forebrain and trajectories for reaching aBST. Therefore, some biasing of PL innervation was evident in more lateral and ventral portions of aBST (i.e., fusiform nucleus), whereas terminal fields from vSUB were slightly more prominent in anterior and medial aspects of aBST (i.e., dorsomedial nucleus), particularly in regions proximal to the anterior commissure. Confocal microscopic analysis in aBST of four animals judged to have appropriately placed injections in all three regions, revealed numerous examples of close appositions of labeled axonal elements from vSUB and/or PL onto $\mathrm{PVH}-$ projecting neurons. Approximately equal proportions of retrogradely labeled neurons were apposed by terminals labeled from PL (53\%) and vSUB (47\%), and 17\% received inputs from both regions.

In two follow-up experiments, quantitative assessments addressed the question of whether elements of this HPAmodulatory network exhibit stress sensitivity. First, animals were subjected to a single acute restraint episode, 1 week after receiving multiple tracer injections (as above), and perfused $2 \mathrm{~h}$ later. Examples were noted of functionally activated $\mathrm{PVH}$-projecting neurons in aBST that were apposed by labeled axonal elements from either PL ( $66 \pm 12$ Fos plus FG neurons) or vSUB ( $59 \pm 10$ Fos plus FG neurons) (Fig. $6 E, F$ ). By proportion, 16 and $15 \%$ of all Fos plus FG neurons in aBST received appositions from PL or vSUB inputs, respectively.

In a second experiment, functional activation of aBSTprojecting neurons in PL and vSUB were examined in animals subjected to a single restraint session (FG injections were placed in aBST; $n=5$ ) (Fig. 7A). Although HF is not prominently regarded as among the more stress-sensitive regions of the limbic forebrain (Li and Sawchenko, 1998), an abundance of pyramidal neurons in vSUB colocalized Fos and tracer $(289 \pm 33)$ (Fig. 7B). Numerous instances of Fos activation were also observed in retrogradely labeled neurons in the more rostral aspects of PL $(245 \pm 62)$ (Fig. $7 C)$. Sress-sensitive aBST-projecting neurons were confined to laminae $\mathrm{V}$ and $\mathrm{VI}$, as previously described (Spencer et al., 2005). Collectively, these experiments suggest that stress-induced functional activation of aBST-projecting neurons in both vSUB and PL are in a position to participate in HPA modulation via a common aBST (GABA) $\rightarrow$ PVH pathway.

\section{Functional evaluation of convergence}

Having provided anatomical evidence for PL and vSUB utilization of a common relay in aBST, we next evaluated the functional relevance of this arrangement. First, we compared the effects of lesions of vSUB and/or PL on central indices of stress-induced 

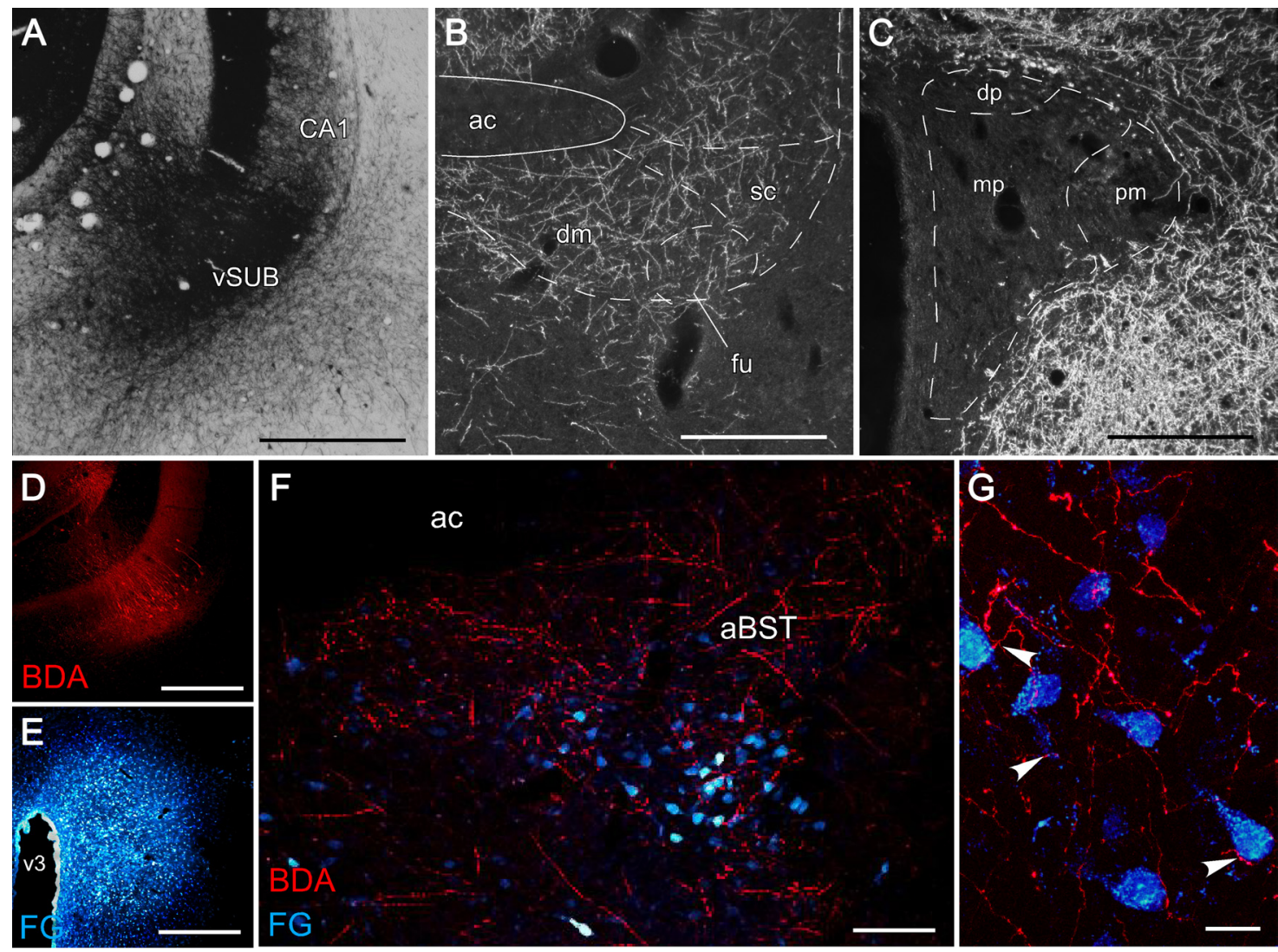

Figure 5. Tracing studies support aBST mediation of vSUB influences on PVH. Top row, Bright- and dark-field photomicrographs showing a large deposit of the anterograde tracer, BDA, centered in vSUB $(\boldsymbol{A})$, and anterogradely labeled fibers and terminals in BSTfu/dm $(\boldsymbol{B})$, and the PVH region $(\boldsymbol{C})$, following such injections. dp, Dorsal parvicellular zone (PVH); $\mathrm{mp}$, medial parvicellular zone (PVH); pm, posterior magnocellular zone (PVH); sc, subcommissural nucleus (BST). Bottom row, Confocal images of dual fluorescence preparations show overlap between vSUB inputs and PVH-projecting neurons in aBST. Animals receiving BDA injections in vSUB (D) and Fluoro-Gold injections in PVH (E) show an intermixing of axonal labeling in aBST with neurons that project to PVH $(\boldsymbol{F})$. $\boldsymbol{F}$, Digital reconstruction of dual fluorescence labeling of BDA and $\mathrm{FG}$ in aBST. The arrows point to examples where terminals were found to be in close apposition with retrogradely labeled elements in single optical planes containing fluorescence labeling for both markers. v3, Third ventricle. Scale bars: $\boldsymbol{A}, 1 \mathrm{~mm} ; \boldsymbol{B}, 300 \mu \mathrm{m} ; \boldsymbol{C}, 250 \mu \mathrm{m} ; \boldsymbol{D}, 500 \mu \mathrm{m} ; \boldsymbol{E}, 250 \mu \mathrm{m} ; \boldsymbol{F}, 100 \mu \mathrm{m} ; \boldsymbol{G}, 30 \mu \mathrm{m}$.

HPA activation. A serial organization would predict that neither single lesion would exert any greater effects than dual ablations, whereas with convergent influences, additivity of single lesion effects would be expected.

Groups of rats received unilateral excitoxin lesion placements in PL, vSUB, both structures, or sham lesions (Fig. 8A). After 2 week survival, all groups were subjected to 30 min restraint and perfused $2 \mathrm{~h}$ later. Comparison of CRF mRNA expression in PVH revealed an overall significant effect as a function of treatment $(p<0.001)$ (Fig. $8 B-E, J)$. Individual comparisons in groups of animals receiving unilateral lesions showed only vSUB lesions resulted in a statistically significant increase $(24 \%)$ relative to sham-operated controls $(p<0.01 ; p=0.09$ in PL-lesioned, compared with sham-lesioned groups). Nonetheless, combined lesions of vSUB and PL resulted in an even greater enhancement of stress-induced CRF mRNA expression in PVH (by 38\%; $p<$ 0.001 ), and also relative to animals receiving lesions of PL or vSUB alone ( $p<0.05$ for each).

Analysis of stress-induced AVP hnRNA expression in PVH revealed main effects of treatment $(p=0.01)$. Individual comparisons in groups of animals receiving unilateral lesions of either PL or vSUB were elevated by 43 and $74 \%$, respectively $(p<0.05$ for each), relative to the sham-lesioned group. Combined lesions of vSUB and PL resulted in a greater enhancement of stressinduced transcriptional activation of AVP hnRNA in PVH relative to the sham-lesioned group (by $164 \% ; p<0.01$ ) and also relative to animals receiving single lesions of either PL (by 50\%) or vSUB (by 33\%). However, the effect of double lesions to PL and vSUB differed reliably from only the PL-lesioned group $(p<$ 0.05 vs $p=0.10$ for the double vs vSUB lesion comparison) (Fig. $8 \mathrm{~F}-J$ ). Collectively, these results are consistent with the idea that vSUB and PL influences are relayed independently, consistent with the idea that they converge onto aBST neurons for imparting additive modulatory influences on HPA output during emotional stress.

In a final experiment, HPA secretory responses before and after 30 min restraint stress were compared in separate groups of animals bearing either sham lesions $(N=6)$, bilateral excitotoxin lesions of vSUB $(N=6)$, or bilateral immunotoxin lesions of GABAergic neurons in aBST $(N=6)$. For the latter group, we used an immunotoxin, antiGAT-1-sap (antiserum to the GABA transporter, GAT-1, coupled to the ribosomal toxin, saporin) that we previously found capable of ablating GABAergic (i.e., GAT-1 and GAD67 mRNA-expressing) neurons in aBST, while largely sparing intermingled neurons of non-GABAergic phenotypes (Radley et al., 2009). In our previous evaluation of antiGAT-1-sap (Radley et al., 2009), we found that effective evaluation of lesion specificity derived from comparison of effects on relative levels of GAD67 and CRF mRNA expression in adjacent series of sections through the aBST. A non-neuroendocrine population of CRF-expressing neurons is well documented to reside within the fusiform and dorsomedial subdivisions of aBST (Day et al., 1999; Dong et al., 2001) and is also implicated in modulating HPA axis output (Choi et al., 2007). Densitometric analyses 

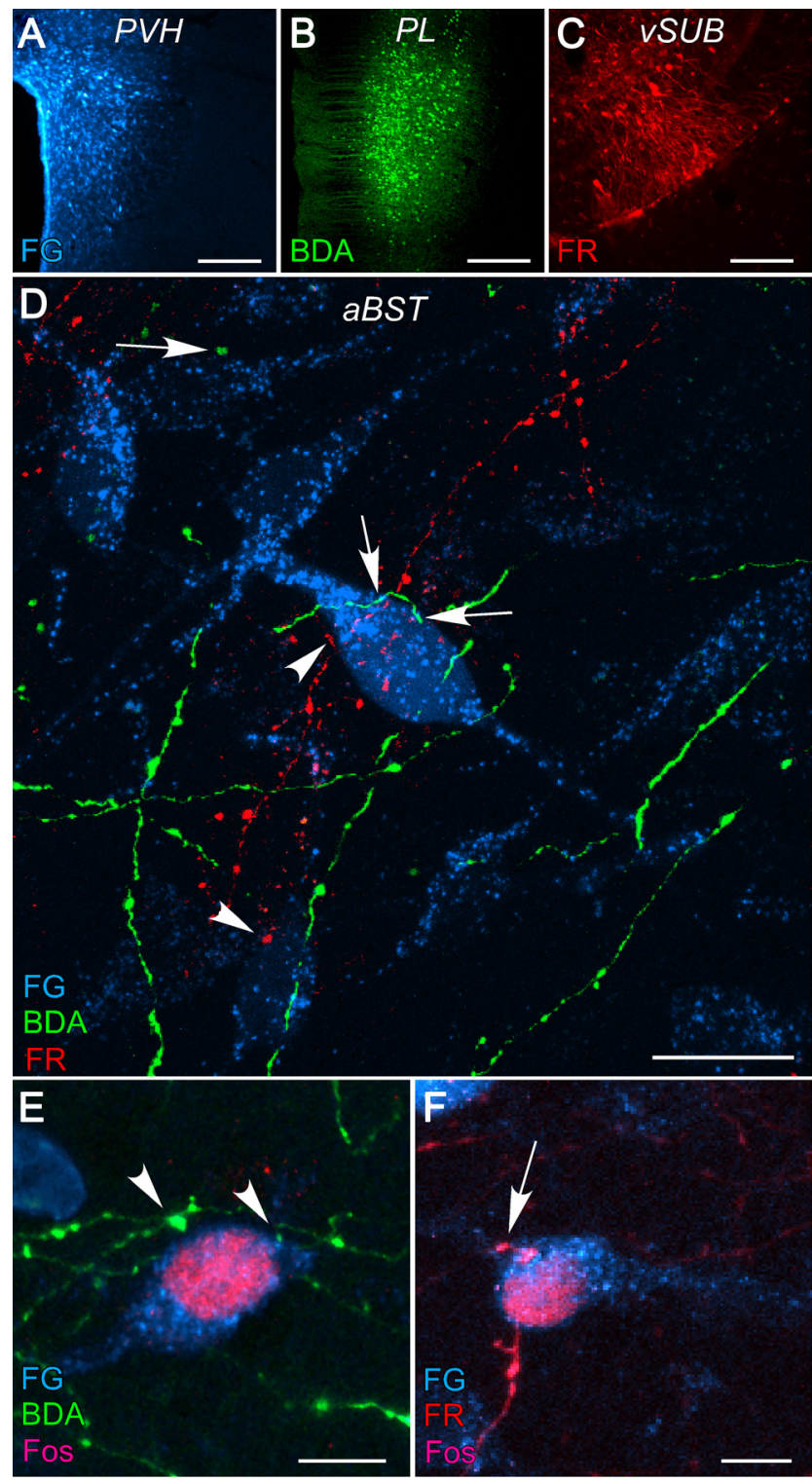

Figure 6. Anatomical evidence for convergence for vSUB and PL projections in aBST. A-C, Representative placements of retrograde tracer $(\mathrm{FG})$ injections in PVH (cyan), and anterograde tracers BDA and FR in PL (green) and vSUB (red), respectively. $\boldsymbol{D}$, The overlap of all three tracers was evaluated in fluorescence preparations using confocal microscopy. Instances of BDA- (arrows) and FR-labeled terminals (arrowhead) were found to make appositions onto single PVHprojecting neurons in aBST, by analysis of single optical planes containing fluorescence labeling for all three markers. $\boldsymbol{E}, \boldsymbol{F}$, After a single restraint stress exposure, numerous instances of Fos-ir nuclei were evident in PVH-projecting neurons containing appositions from BDA- (left) and FR-labeled (right) terminals. Scale bars: $\boldsymbol{A}-\boldsymbol{C}, 250 \mu \mathrm{m} ; \boldsymbol{D}, 150 \mu \mathrm{m} ; \boldsymbol{E}, 10 \mu \mathrm{m} ; \boldsymbol{F}, 5 \mu \mathrm{m}$.

revealed a significant decrease (by 67\%; $p<0.05$ ) in GAD67 mRNA in aBST following GAT-1-sap injections, but no effect on CRF mRNA expression in the affected region ( $p=0.7)$. Reconstructions of vSUB excitotoxin and aBST immunotoxin lesions are provided in Figure $9 A$.

Mixed-design ANOVA of ACTH data, with time of blood sampling treated as a within-subjects factor, demonstrated main effects of lesion status $(p<0.05)$ and time $(p<0.0001)$, as well as a significant interaction between these variables $(p<0.001)$. Within-group measures revealed significant increases in peak values of ACTH immediately after the termination of restraint (30 min; $p<0.05$ for each). All values were restored to prestress levels by $60 \mathrm{~min}$, except for those of immunotoxin-lesioned ani-
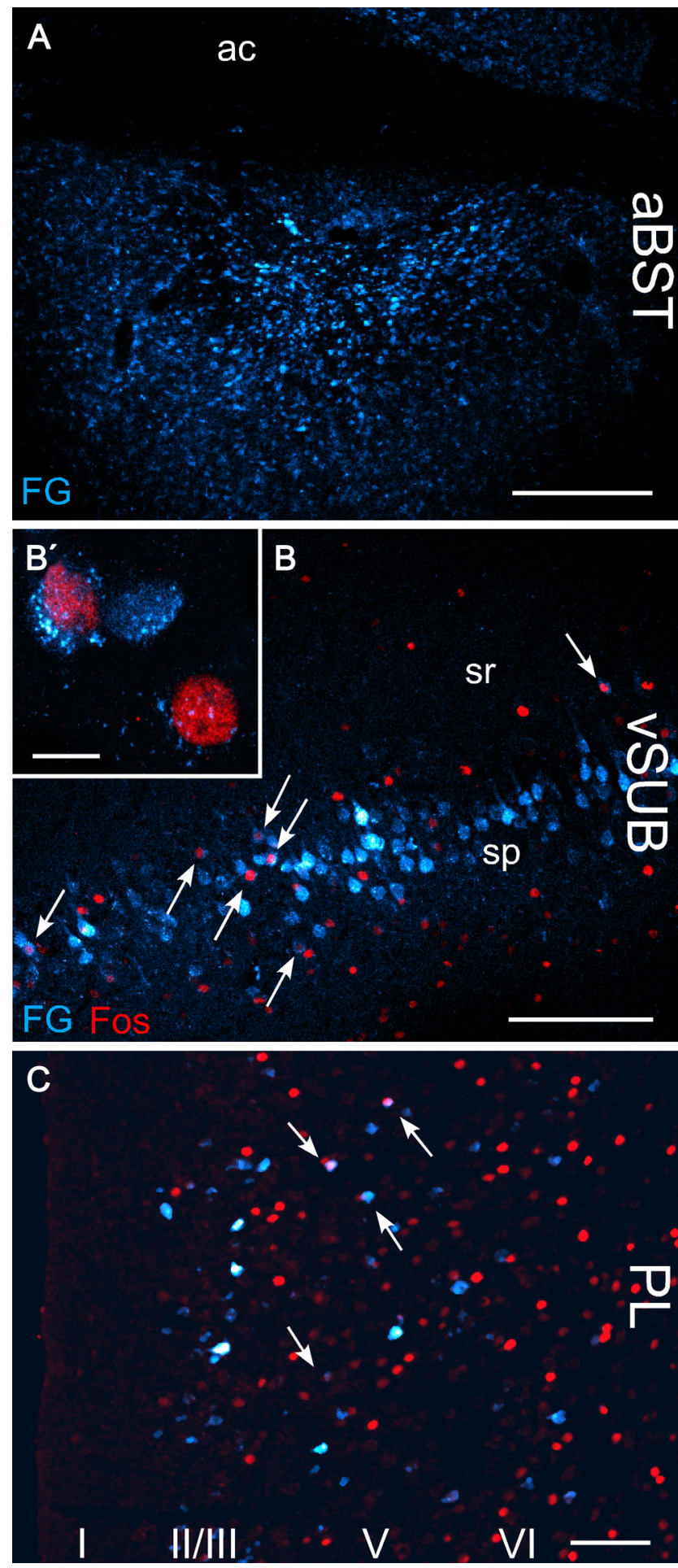

Figure 7. aBST-projecting neurons in VSUB and PL are stress sensitive. Retrograde tracer injections of FG in aBST $(\boldsymbol{A})$ reveal extensive labeling of neurons in the principal cell layer in vSUB $(\boldsymbol{B})$. Many of these neurons also show restraint-induced Fos immunoreactivity (arrows). sp, Stratum pyramidale; $\mathrm{sr}$, stratum radiatum. In the same animals, colocalization of $\mathrm{FG}$ and Fos $(\boldsymbol{C})$ is also seen in PL (arrows), particularly in deeper layers (indicated by roman numerals). Scale bars: $\boldsymbol{A}, 250 \mu \mathrm{m} ; \boldsymbol{B}, 100 \mu \mathrm{m} ; \boldsymbol{B}^{\prime}, 10 \mu \mathrm{m} ; \boldsymbol{C}, 150 \mu \mathrm{m}$.

mals (60 min; $p<0.05$ ), which remained elevated until 90 min after the initiation of restraint. In vSUB and immunotoxinlesioned groups, peak levels of plasma ACTH were significantly greater than those of sham-lesioned animals (by 2.2- and 2.4fold, respectively) immediately following the termination of re- 

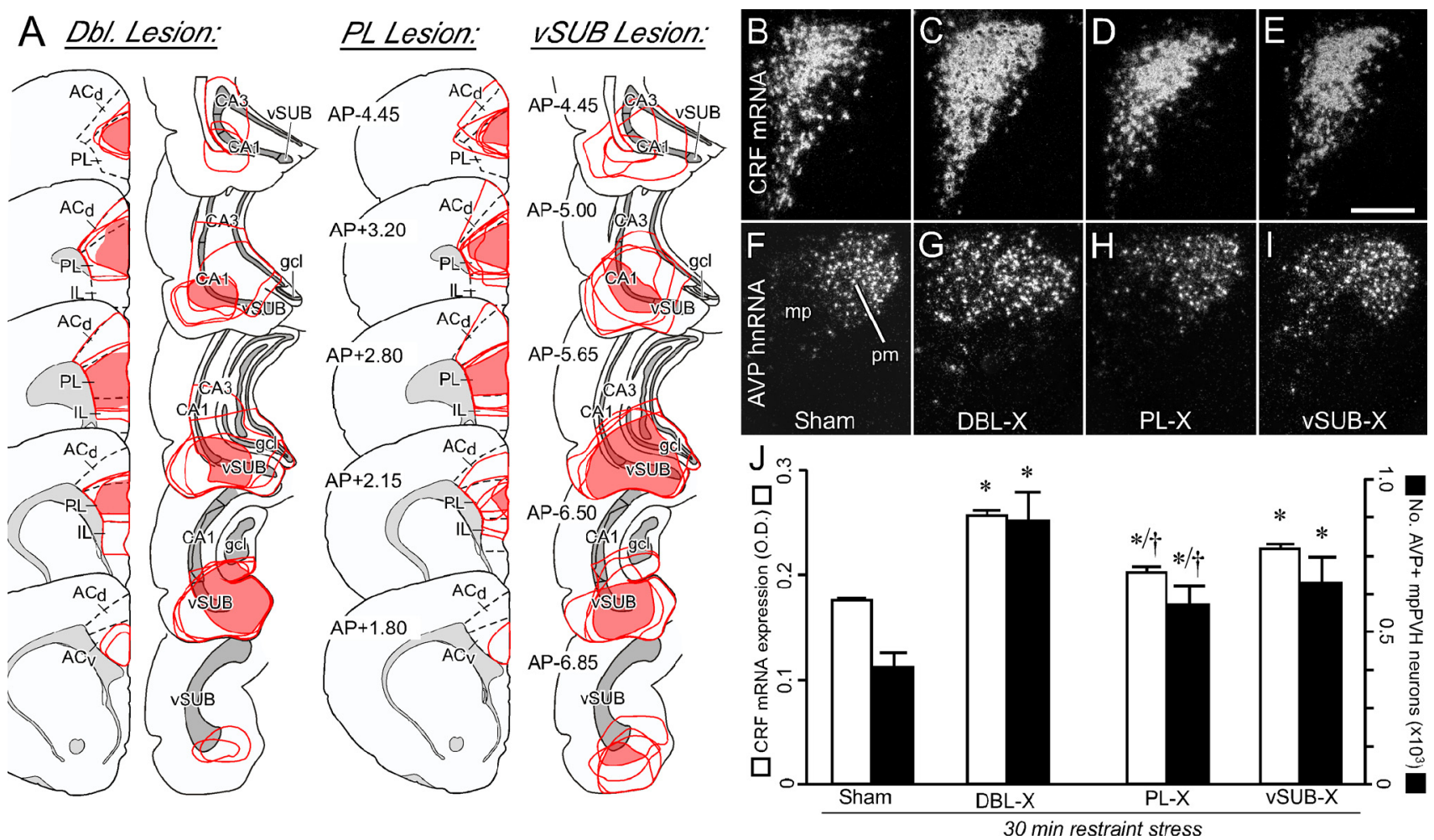

Figure 8. Additive effects of unilateral excitotoxin lesions of PL and VSUB on central indices of stress-induced HPA activation. $A$, Reconstruction of lesion placements in groups of rats bearing unilateral excitotoxin injections in vSUB (right), PL (middle), and both sites (i.e., "Dbl. lesion") (left). The solid areas of red represent the region of damage common to all members of each group, and outlines the extent of individual lesions as determined, in reconstructions based on Nissl material. Atlas plates are adapted from those of Swanson (1992); distance in millimeters relative to bregma is indicated. ACd, Anterior cingulate area, dorsal part; ACV, anterior cingulate area, ventral part; IL, infralimbic area; PL, prelimbic area; vSUB, ventral subiculum. Dark-field photomicrographs show representative examples of CRF mRNA $(\boldsymbol{B}-\boldsymbol{E})$ and AVP hnRNA $(\boldsymbol{F}-\boldsymbol{I})$ expression in PVH as a function of lesion status. $\boldsymbol{J}$, Mean + SEM relative levels of (RF mRNA expression (open bars) and number of medial parvicellular neurons in PVH displaying AVP hnRNA signal (black bars) in various treatment groups. All lesioned groups show significant increases in central measures of restraint-induced HPA activation, with the responses of animals bearing double lesions (of PL and VSUB) being reliably greater that those of the PL-lesioned group. ${ }^{*} p<0.05$, differs significantly from the sham-lesioned group; ${ }^{\dagger} p<0.05$, differs significantly from dual-lesioned animals. $n=4-5$ per group. Scale bar: $150 \mu \mathrm{m}$ (applies to all).

straint (30 min; $p<0.05$ for each); however, these values did not differ reliably from one another $(p=0.7)$ (Fig. 9B).

Plasma corticosterone data showed similar main effects of lesion status $(p<0.001)$ and time $(p<0.0001)$. Whereas peak levels of plasma corticosterone were significantly elevated in each group at the termination of restraint (30 min; $p<0.05$ for each), there were no significant differences as a function of lesion status $(p=0.9)$. Nonetheless, plasma corticosterone levels in the aBST immunotoxin-lesioned group was significantly elevated compared with vSUB and sham-lesioned groups ( $p<0.05$, for each) (Fig. 9C). Moreover, within-group analyses revealed that animals with aBST immunotoxin lesions showed a more protracted corticosterone response, displaying reliable elevations relative to baseline values through $90 \mathrm{~min}$, compared with $60 \mathrm{~min}$ for vSUB and sham-lesioned animals. Basal plasma levels of ACTH and corticosterone showed a mild, albeit consistent, elevation in the aBST immunotoxin-lesioned group, compared with vSUB and sham-lesioned groups ( $p<0.05$, respectively). These data provide evidence that aBST plays a more prominent HPA-inhibitory role than vSUB, supporting the possibility that the former may serve as a clearinghouse for multiple limbic forebrain influences over the stress axis.

\section{Discussion}

Here, we have applied a strategy used previously to delineate candidate intermediaries providing for $\mathrm{mPFC}$ inhibition of HPA responses to acute emotional stress to elucidate the circuitry pro- viding for a parallel involvement of another limbic forebrain structure, the HF (specifically vSUB). The results implicate an HPA-inhibitory role for GABAergic neurons of the aBST in both contexts. Anatomical tracing studies performed in experimental settings support the existence of stress-sensitive, aBST-projecting neurons in $\mathrm{VSUB}$, whose projections to aBST commingle with those of $\mathrm{mPFC}$ and provide convergent inputs to at least some identified PVH-projecting neurons. Functional experiments support additive effects of mPFC and vSUB lesions on central and hormonal indices of stress-induced HPA output. Collectively, these data endorse the idea that the aBST receives and integrates convergent input from HF and $\mathrm{mPFC}$ for the inhibitory control of emotional stress-induced HPA activity.

\section{Neural pathways subserving HF HPA-inhibitory influences}

Work done over the past several decades supports the involvement of the HF in both tonic and phasic negative-feedback regulation of the HPA axis (Feldman and Conforti, 1980; Sapolsky et al., 1984; Kovács and Makara, 1988; Herman et al., 1989; Jacobson and Sapolsky, 1991). Thus, damage to hippocampus or fimbria/fornix produces exaggerated stress-induced HPA responses (Feldman and Conforti, 1980; Sapolsky et al., 1984; Herman et al., 1989). While previous studies tended to focus on the dorsal hippocampus as the principal seat of HPA axis regulation, Herman et al. (1995) directed attention to the ventral hippocampus, notably vSUB, in this context. Much of the rationale for this shift in emphasis derived from anatomical evidence that vSUB is the 

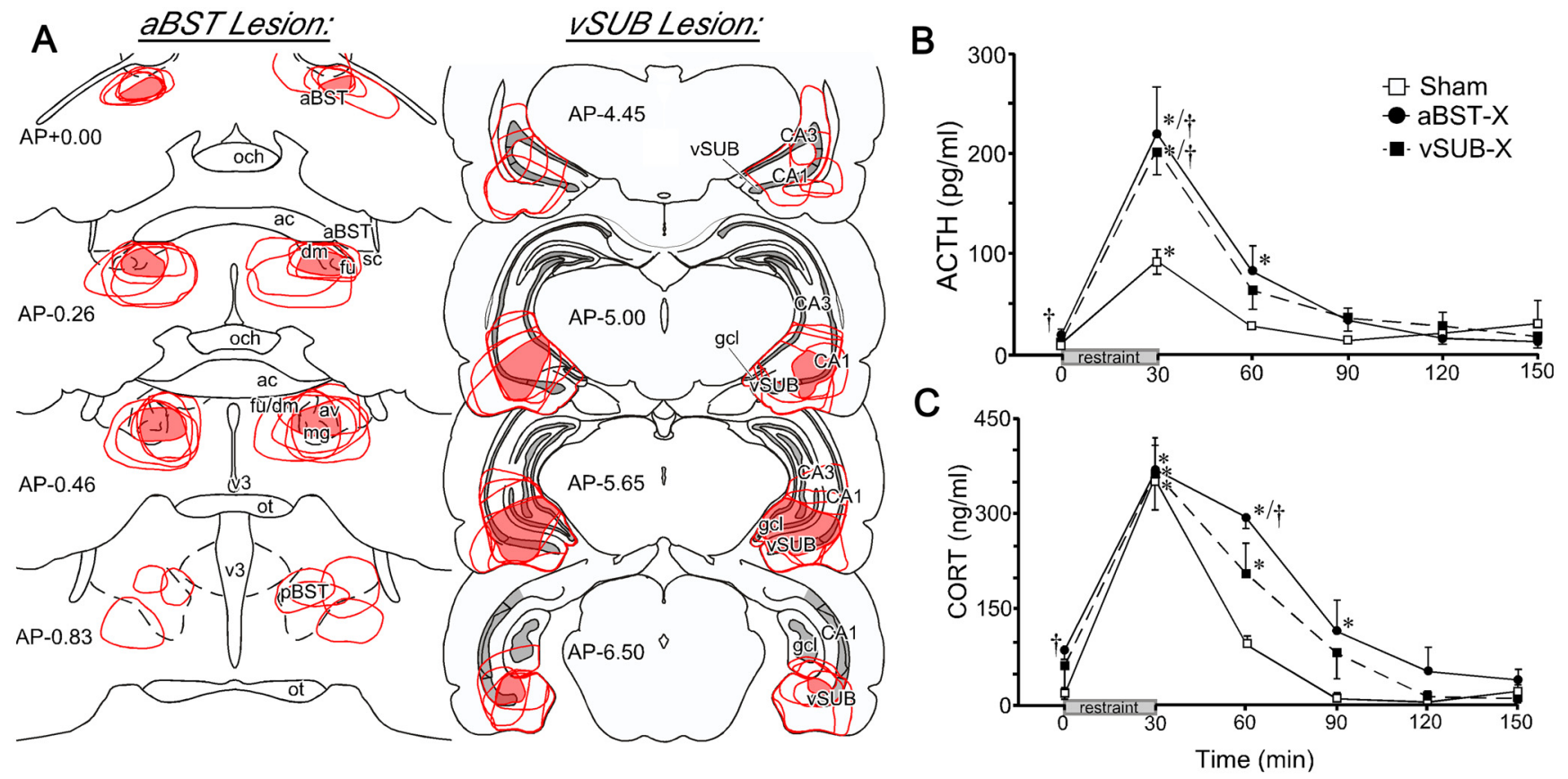

Figure 9. Greater augmentation of HPA secretory responses by ablation of GABAergic neurons in aBST than vSUB lesions. $A$, Reconstructions of immunotoxin lesions of aBST (left) and excitotoxin lesions of vSUB (right). The solid areas of red represent the region of damage common to all members of each group, and individual lesions are shown as outlines. Immunotoxin lesion extent was defined by the absence of GAD67 mRNA expression, whereas ibotenic acid lesions were reconstructed based on cell loss in Nissl material. Atlas plates are adapted from those of Swanson (1992); distance in millimeters relative to bregma is indicated. aBST, Bed nucleus of the stria terminalis, anterior division; av, anteroventral area (BST); fu/dm, fusiform/dorsomedial nuclei (BST); $\mathrm{mg}$, magnocellular nucleus (BST); pBST, posterior division, BST; PS, parastrial nucleus; sc, subcommissural zone (BST). Shown are mean \pm SEM plasma ACTH (B) and corticosterone (C) levels in sham, VSUB-, and GAT-1-saporin immunotoxin-lesioned animals before $(0 \mathrm{~min})$ and at varying intervals after acute restraint exposure. Whereas stress significantly increased plasma levels of ACTH in all treatment groups, animals bearing immunotoxin lesions showed a prolonged elevation of ACTH (60 min; $p<0.05$ ), based upon within-group comparison with prestress levels, and both lesion groups showed significantly higher peak levels of ACTH compared with sham-lesioned rats ( $30 \mathrm{~min} ; p<0.05$ ). Although there were no differences in peak values of corticosterone as a function of experimental treatment, immunotoxin-lesioned animals showed a prolonged elevation based upon both within-group (at 60 and $90 \mathrm{~min} ; p<0.05$ for each) and between-group measures ( 60 min; $p<0.05)$. Notably, prestress levels of ACTH and corticosterone were also significantly elevated in the immunotoxin- compared with vSUB-and sham-lesioned groups $(0$ min; $p<0.05) .{ }^{*} p<0.05$, differs significantly from basal ( $0 \mathrm{~min})$ values within each group; ${ }^{\dagger} p<0.05$, differs significantly from sham-lesioned animals. $n=6$ per group.

major source of subcortical projections that target hypothalamic and adjoining basal forebrain cell groups that innervate the $\mathrm{PVH}$ (Cullinan et al., 1993), which are implicated in regulating HPA activity (Cullinan et al., 1993, 1996; Roland and Sawchenko, 1993; Boudaba et al., 1996). More recent evidence has led to a clearer appreciation that hippocampal function is differentiated in a dorsal-ventral (or septal-temporal) manner, with dorsal and ventral HF being preferentially involved in memory-related and affective functions, respectively (Moser and Moser, 1998; Kjelstrup et al., 2002; Dong et al., 2009; Fanselow and Dong, 2010). This view is consistent with the notion supported here that ventral HF is an important modulator of stress-induced HPA activity.

While uncertainty has remained as to the specific target(s) of vSUB outputs that mediate its HPA-modulatory effects, the present results implicate PVH-projecting GABAergic neurons in aBST as providing such a relay. After verifying that excitotoxin lesions of vSUB augment central indices of acute restraint stressinduced HPA activation, we found that PVH-projecting neurons in aBST showed a reliable diminution of stress-induced functional activation (Fos expression) following vSUB lesions, and colocalization experiments identified this same population of neurons as predominantly GABAergic. We found previously that selective ablation of GABAergic neurons in aBST produces exaggerated emotional stress-induced HPA responses (Radley et al., 2009), supporting the relevance of a vSUB $\rightarrow$ aBST (GABA) $\rightarrow$ PVH pathway in imposing HF inhibition of the stress axis. Furthermore, we observed a substantial overlap between vSUB terminal fields in aBST and PVH-projecting neurons, and that

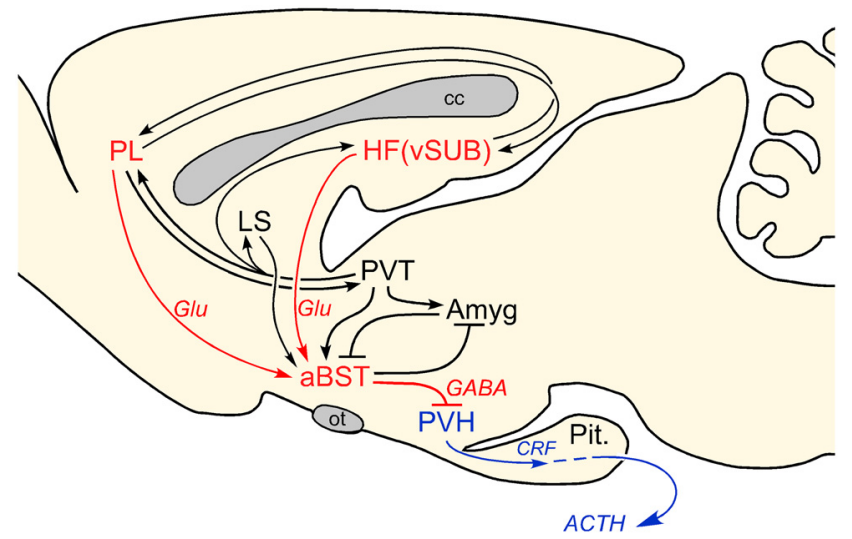

Figure 10. Proposed role of aBST as an integrator of limbic forebrain influences on emotional stress-induced HPA output. The data support the pathways highlighted in red, with aBST providing an important source of GABAergic innervation of PVH, and relaying limbic cortical influences from HF and mPFC (i.e., PL). Other forebrain cell groups known to influence HPA output (highlighted in black), notably via GC receptor-mediated negative feedback, also project to aBST, whose integrated output targets PVH directly. Like vSUB and PL, these regions [lateral septum (LS); paraventricular nucleus of the thalamus (PVT); amygdala (Amyg)] provide no substantial direct innervation of PVH but do issue projections to the aBST (Shin et al., 2008).

neurons in this circuit (i.e., aBST-projecting vSUB neurons, $\mathrm{PVH}$-projecting neurons in aBST that reside within vSUB terminal fields) exhibit restraint stress sensitivity. This does not preclude an involvement of other pathways from vSUB, particularly more diffuse pathways that may access aBST or that could bypass 
this circuitry en route to PVH. Nonetheless, these results endorse this GABAergic cell group in aBST as an important way station for the top-down, modulatory control of the neuroendocrine stress response.

\section{Convergence of mPFC and HF outputs onto aBST}

The fact that vSUB may act through a common relay as mPFC raises the possibility that aBST may serve a broader role than has been appreciated in modulating stress-inhibitory influences of the limbic forebrain. Confocal laser-scanning microscopic analysis of material from animals bearing multiple tracer deposits showed that PL and vSUB efferents converged onto the very aspects of, and even onto individual neurons within, aBST that provide GABAergic input to PVH (Fig. 6). Axonal elements labeled from PL and vSUB were found to be juxtaposed to PVHprojecting aBST neurons in relatively equal proportions, with $17 \%$ of these receiving appositions from both sources. Appositions were defined here as anterogradely labeled varicosities that directly abutted FG-labeled perikarya or dendrites in single thin optical sections. Electron microscopy remains the definitive tool for defining true synaptic relationships; confocal laser scanning microscopy has come to be accepted as providing a reasonable approximation (Mason et al., 1992; Herman et al., 2008; Hohensee et al., 2008; Geerling et al., 2010) and offers the advantage of readily allowing of multiple labeling applications. It is worth noting that variations in (1) the accuracy of tracer injections, particularly with individual animals receiving as many as three separate placements (PL, vSUB, PVH), (2) the extent to which any individual tracer deposit samples the targeted cell group, and (3) the sensitivity with which individual tracers label projections of interest, likely result in an underestimation of the strength of individual projections and, in the present case, the extent to which their outputs may converge on a shared target population. As inputs to aBST arising from PL and vSUB are of moderate density and aBST is not prominently traversed by axons-ofpassage arising from the two cortical fields (Sesack et al., 1989; Canteras and Swanson, 1992), it seems reasonable to conclude that our findings underestimate the PL and vSUB innervation of, and convergence upon, $\mathrm{PVH}$-projecting aBST neurons.

One lingering issue concerns the extent to which convergence of PL and vSUB inputs is manifest onto single PVH-projecting neurons in aBST. Whereas numerous instances were noted of appositions from PL or vSUB projections onto single stresssensitive PVH-projecting neurons, no examples were found of convergence from both regions onto the same subpopulation. This is likely attributable to the substantial drop off in the sensitivity of Fos detection by immunofluorescence, compared with immunoperoxidase (our unpublished observations), and the aforementioned limitations of combining three tracer injections. Nonetheless, it is reasonable to speculate that subtle topographical differences noted in PL and vSUB innervation patterns in aBST could suggest some parcellation of these influences onto different subpopulations. Whether PL and vSUB influences modulate stress-induced HPA output via convergence onto single PVH-projecting neurons, within different aspects of aBST, or some combination thereof, will be a topic of future investigation, these data highlight the fact that aBST intercedes for both limbic cortical influences over emotional stress-induced HPA output.

\section{Features of HPA-modulatory network in response emotional stress}

Examination of immediate-early gene induction patterns have shown that exposure to any of a range of acute emotional stres- sors activates a stereotyped and highly interconnected set of cell groups in the limbic forebrain and associated cortical structures (Cullinan et al., 1995; Campeau et al., 1997; Li and Sawchenko, 1998; Dayas et al., 2001) (Fig. 10). While a good deal is known about how individual components affect stress-induced HPA output (Diorio et al., 1993; Herman et al., 1995, 2003; Bhatnagar and Dallman, 1998; Dayas et al., 2001; Radley et al., 2006), the overall organization of the network with respect to how its influences are imposed on the PVH has remained elusive. The present study provides evidence that a relatively discrete GABAergic cell group in aBST intercedes for at least two of these influences (i.e., mPFC and HF) on CRF-expressing HPA effector neurons in PVH. In support of this conclusion, we find that (1) aBSTprojecting cell groups in PL and vSUB, and PVH-projecting GABAergic neurons in aBST, are each responsive to a prototypic emotional stressor; (2) single versus dual lesion studies support an additivity of HF and mPFC stress-inhibitory influences on central indices of HPA activation, consistent with the idea that their influences are summated at aBST; (3) immunotoxin ablation of aBST GABAergic neurons results in a more profound enhancement of emotional stress-induced HPA output than do lesions of one upstream component of the stress-inhibitory network. Moreover, despite the fact that the MPFC and HF are interconnected (e.g., via the entorhinal cortex) (Swanson and Köhler, 1986; Vertes, 2004), the additivity of effects observed after combined versus separate lesions of these regions do not support a serial processing arrangement underlying their modulatory effects on emotional stress-induced HPA output. While it remains to be determined how generalized a convergent organization may be, the available connectivity data indicate that many, if not all, limbic forebrain sites that modulate HPA function may function cooperatively via their innervation of aBST.

An important next step will be to determine the extent to which the aBST may serve a general role in integrating excitatory (e.g., from the amygdala) and inhibitory influences [from PL, vSUB, septum, posterior paraventricular thalamic nucleus (PVTp)] over the stress axis by way of aBST-GABAergic inputs to the PVH (Fig. 10). Such an examination is warranted, based on the lack of any substantial direct innervation of PVH from these limbic forebrain cell groups, and the fact that each projects to the aBST (Shin et al., 2008). That the aBST also receives inputs from most hypothalamic and brainstem structures implicated in stress-induced HPA activation (Shin et al., 2008) may indicate an even broader role in the integrative control of axis output during emotional stress. Another lingering issue derives from evidence that several nodes of the limbic forebrain network (e.g., septum, HF, mPFC, PVTp) are implicated as sites for GC receptormediated feedback control of HPA output (Dobrakovová et al., 1982; Sapolsky et al., 1984; Diorio et al., 1993; Jaferi and Bhatnagar, 2006), raising the possibility that aBST may also serve as a clearinghouse for this function. Additional work is required to dissect the extent to which the ostensibly distributed feedback effects arising from $\mathrm{GC}$ actions at these limbic forebrain sites may be exerted through common intermediaries, such as aBST, or via multiple parallel paths.

\section{References}

Antoni FA (1986) Hypothalamic control of adrenocorticotropin secretion: advances since the discovery of 41-residue corticotropin-releasing factor. Endocr Rev 7:351-378.

Bhatnagar S, Dallman M (1998) Neuroanatomical basis for facilitation of hypothalamic-pituitary-adrenal responses to a novel stressor after chronic stress. Neuroscience 84:1025-1039.

Boudaba C, Szabó K, Tasker JG (1996) Physiological mapping of local in- 
hibitory inputs to the hypothalamic paraventricular nucleus. J Neurosci 16:7151-7160.

Bremner JD, Randall P, Scott TM, Bronen RA, Seibyl JP, Southwick SM, Delaney RC, McCarthy G, Charney DS, Innis RB (1995) MRI-based measurement of hippocampal volume in patients with combat-related posttraumatic stress disorder. Am J Psychiatry 152:973-981.

Campeau S, Falls WA, Cullinan WE, Helmreich DL, Davis M, Watson SJ (1997) Elicitation and reduction of fear: behavioural and neuroendocrine indices and brain induction of the immediate-early gene c-fos. Neuroscience 78:1087-1104.

Canteras NS, Swanson LW (1992) Projections of the ventral subiculum to the amygdala, septum, and hypothalamus: a PHAL anterograde tracttracing study in the rat. J Comp Neurol 324:180-194.

Carroll, Curtis GC, Mendels J (1976) Neuroendocrine regulation in depression. I. Limbic system-adrenocortical dysfunction. Arch Gen Psychiatry 33:1039-1044.

Chang HT, Kuo H, Whittaker JA, Cooper NG (1990) Light and electron microscopic analysis of projection neurons retrogradely labeled with Fluoro-Gold: notes on the application of antibodies to Fluoro-Gold. J Neurosci Methods 35:31-37.

Choi DC, Furay AR, Evanson NK, Ostrander MM, Ulrich-Lai YM, Herman JP (2007) Bed nucleus of the stria terminalis subregions differentially regulate hypothalamic-pituitary-adrenal axis activity: implications for the integration of limbic inputs. J Neurosci 27:2025-2034.

Cullinan WE, Herman JP, Watson SJ (1993) Ventral subicular interaction with the hypothalamic paraventricular nucleus: evidence for a relay in the bed nucleus of the stria terminalis. J Comp Neurol 332:1-20.

Cullinan WE, Herman JP, Battaglia DF, Akil H, Watson SJ (1995) Pattern and time course of immediate early gene expression in rat brain following acute stress. Neuroscience 64:477-505.

Cullinan WE, Helmreich DL, Watson SJ (1996) Fos expression in forebrain afferents to the hypothalamic paraventricular nucleus following swim stress. J Comp Neurol 368:88-99.

Day HE, Curran EJ, Watson SJ Jr, Akil H (1999) Distinct neurochemical populations in the rat central nucleus of the amygdala and bed nucleus of the stria terminalis: evidence for their selective activation by interleukin1beta. J Comp Neurol 413:113-128.

Dayas CV, Buller KM, Crane JW, Xu Y, Day TA (2001) Stressor categorization: acute physical and psychological stressors elicit distinctive recruitment patterns in the amygdala and in medullary noradrenergic cell groups. Eur J Neurosci 14:1143-1152.

Diorio D, Viau V, Meaney MJ (1993) The role of the medial prefrontal cortex (cingulate gyrus) in the regulation of hypothalamic-pituitaryadrenal responses to stress. J Neurosci 13:3839-3847.

Dobrakovová M, Kvetnanský R, Torda T, Murgas K (1982) Changes of plasma and adrenal catecholamines and corticosterone in stressed rats with septal lesions. Physiol Behav 29:41-45.

Dong HW, Swanson LW (2006) Projections from the bed nucleus of the stria terminalis, anteromedial area: cerebral hemispheric integration of neuroendocrine, autonomic, and behavioral aspects of energy balance. J Comp Neurol 494:142-178.

Dong HW, Petrovich GD, Watts AG, Swanson LW (2001) Basic organization of projections from the oval and fusiform nuclei of the bed nuclei of the stria terminalis in adult rat brain. J Comp Neurol 436:430-455.

Dong HW, Swanson LW, Chen L, Fanselow MS, Toga AW (2009) Genomic-anatomic evidence for distinct functional domains in hippocampal field CA1. Proc Natl Acad Sci U S A 106:11794-11799.

Fanselow MS, Dong HW (2010) Are the dorsal and ventral hippocampus functionally distinct structures? Neuron 65:7-19.

Feldman S, Conforti N (1980) Participation of the dorsal hippocampus in the glucocorticoid feedback effect on adrenocortical activity. Neuroendocrinology 30:52-55.

Feldman S, Conforti N (1981) Effects of hypothalamic deafferentations on adrenocortical responses in the rat following hippocampal stimulation. Exp Brain Res 44:232-234.

Feldman S, Saphier D, Conforti N (1987) Hypothalamic afferent connections mediating adrenocortical responses that follow hippocampal stimulation. Exp Neurol 98:103-109.

Geerling JC, Shin JW, Chimenti PC, Loewy AD (2010) Paraventricular hypothalamic nucleus: axonal projections to the brainstem. J Comp Neurol 518:1460-1499.
Herman JP, Mueller NK (2006) Role of the ventral subiculum in stress integration. Behav Brain Res 174:215-224.

Herman JP, Schäfer MK, Young EA, Thompson R, Douglass J, Akil H, Watson SJ (1989) Evidence for hippocampal regulation of neuroendocrine neurons of the hypothalamo-pituitary-adrenocortical axis. J Neurosci 9:3072-3082.

Herman JP, Cullinan WE, Morano MI, Akil H, Watson SJ (1995) Contribution of the ventral subiculum to inhibitory regulation of the hypothalamopituitary-adrenocortical axis. J Neuroendocrinol 7:475-482.

Herman JP, Dolgas CM, Carlson SL (1998) Ventral subiculum regulates hypothalamo-pituitary-adrenocortical and behavioural responses to cognitive stressors. Neuroscience 86:449-459.

Herman JP, Figueiredo H, Mueller NK, Ulrich-Lai Y, Ostrander MM, Choi DC, Cullinan WE (2003) Central mechanisms of stress integration: hierarchical circuitry controlling hypothalamo-pituitary-adrenocortical responsiveness. Front Neuroendocrinol 24:151-180.

Herman JP, Flak J, Jankord R (2008) Chronic stress plasticity in the hypothalamic paraventricular nucleus. Prog Brain Res 170:353-364.

Hohensee S, Bleiss W, Duch C (2008) Correlative electron and confocal microscopy assessment of synapse localization in the central nervous system of an insect. J Neurosci Methods 168:64-70.

Hurley KM, Herbert H, Moga MM, Saper CB (1991) Efferent projections of the infralimbic cortex of the rat. J Comp Neurol 308:249-276.

Jacobson L, Sapolsky R (1991) The role of the hippocampus in feedback regulation of the hypothalamic-pituitary-adrenocortical axis. Endocr Rev 12:118-134.

Jaferi A, Bhatnagar S (2006) Corticosterone can act at the posterior paraventricular thalamus to inhibit hypothalamic-pituitary-adrenal activity in animals that habituate to repeated stress. Endocrinology 147:4917-4930.

Kjelstrup KG, Tuvnes FA, Steffenach HA, Murison R, Moser EI, Moser MB (2002) Reduced fear expression after lesions of the ventral hippocampus. Proc Natl Acad Sci U S A 99:10825-10830.

Kovács KJ, Makara GB (1988) Corticosterone and dexamethasone act at different brain sites to inhibit adrenalectomy-induced adrenocorticotropin hypersecretion. Brain Res 474:205-210.

Kovács KJ, Sawchenko PE (1996) Sequence of stress-induced alterations in indices of synaptic and transcriptional activation in parvocellular neurosecretory neurons. J Neurosci 16:262-273.

Kovács KJ, Földes A, Sawchenko PE (2000) Glucocorticoid negative feedback selectively targets vasopressin transcription in parvocellular neurosecretory neurons. J Neurosci 20:3843-3852.

Li HY, Sawchenko PE (1998) Hypothalamic effector neurons and extended circuitries activated in "neurogenic" stress: a comparison of footshock effects exerted acutely, chronically, and in animals with controlled glucocorticoid levels. J Comp Neurol 393:244-266.

Lorente de Nó R (1934) Studies on the structure of the cerebral cortex. II. Continuation of the study of the ammonic system. J Psychol Neurol 46:113-177.

Ma XM, Levy A, Lightman SL (1997) Rapid changes in heteronuclear RNA for corticotropin-releasing hormone and arginine vasopressin in response to acute stress. J Endocrinol 152:81-89.

Mason P, Back SA, Fields HL (1992) A confocal laser microscopic study of enkephalin-immunoreactive appositions onto physiologically identified neurons in the rostral ventromedial medulla. J Neurosci 12:4023-4036.

McEwen BS (2001) Plasticity of the hippocampus: adaptation to chronic stress and allostatic load. Ann N Y Acad Sci 933:265-277.

McEwen BS, Weiss JM, Schwartz LS (1968) Selective retention of corticosterone by limbic structures in rat brain. Nature 220:911-912.

Moser MB, Moser EI (1998) Functional differentiation in the hippocampus. Hippocampus 8:608-619.

Ottenweller JE, Natelson BH, Pitman DL, Drastal SD (1989) Adrenocortical and behavioral responses to repeated stressors: toward an animal model of chronic stress and stress-related mental illness. Biol Psychiatry 26:829841.

Plotsky PM (1991) Pathways to the secretion of adrenocorticotropin: a view from the portal*. J Neuroendocrinol 3:1-9.

Priou A, Oliver C, Grino M (1993) In situ hybridization of arginine vasopressin (AVP) heteronuclear ribonucleic acid reveals increased AVP gene transcription in the rat hypothalamic paraventricular nucleus in response to emotional stress. Acta Endocrinol 128:466-472.

Radley JJ, Arias CM, Sawchenko PE (2006) Regional differentiation of the 
medial prefrontal cortex in regulating adaptive responses to acute emotional stress. J Neurosci 26:12967-12976.

Radley JJ, Williams B, Sawchenko PE (2008) Noradrenergic innervation of the dorsal medial prefrontal cortex modulates hypothalamo-pituitaryadrenal responses to acute emotional stress. J Neurosci 28:5806-5816.

Radley JJ, Gosselink KL, Sawchenko PE (2009) A discrete GABAergic relay mediates medial prefrontal cortical inhibition of the neuroendocrine stress response. J Neurosci 29:7330-7340.

Rivier C, Vale W (1983) Interaction of corticotropin-releasing factor and arginine vasopressin on adrenocorticotropin secretion in vivo. Endocrinology 113:939-942.

Rivier C, Rivier J, Vale W (1982) Inhibition of adrenocorticotropic hormone secretion in the rat by immunoneutralization of corticotropinreleasing factor. Science 218:377-379.

Roland BL, Sawchenko PE (1993) Local origins of some GABAergic projections to the paraventricular and supraoptic nuclei of the hypothalamus in the rat. J Comp Neurol 332:123-143.

Rose M (1929) Cytoarchiteknischer Atlas der Maus. J Psychol Neurol 40:1-51.

Sapolsky RM (1996) Why stress is bad for your brain. Science 273:749-750.

Sapolsky RM, Krey LC, McEwen BS (1984) Glucocorticoid-sensitive hippocampal neurons are involved in terminating the adrenocortical stress response. Proc Natl Acad Sci U S A 81:6174-6177.

Sapolsky RM, Krey LC, McEwen BS (1985) Prolonged glucocorticoid exposure reduces hippocampal neuron number: implications for aging. J Neurosci 5:1222-1227.

Sawchenko PE, Cunningham ETJ, Mortrud MT, Pfeiffer SW, Gerfen CR (1990) Phaseolus vulgaris-leucoagglutanin (PHA-L) anterograde axonal transport technique. Methods Neurosci 3:247-260.

Schmued LC, Fallon JH (1986) Fluoro-Gold: a new fluorescent retrograde axonal tracer with numerous unique properties. Brain Res 377:147-154.

Sesack SR, Deutch AY, Roth RH, Bunney BS (1989) Topographical organization of the efferent projections of the medial prefrontal cortex in the rat: an anterograde tract-tracing study with Phaseolus vulgaris leucoagglutinin. J Comp Neurol 290:213-242.

Sheline YI, Wang PW, Gado MH, Csernansky JG, Vannier MW (1996) Hippocampal atrophy in recurrent major depression. Proc Natl Acad Sci U S A 93:3908-3913.

Shin JW, Geerling JC, Loewy AD (2008) Inputs to the ventrolateral bed nucleus of the stria terminalis. J Comp Neurol 511:628-657.
Shu SY, Ju G, Fan LZ (1988) The glucose oxidase-DAB-nickel method in peroxidase histochemistry of the nervous system. Neurosci Lett 85:169-171.

Simmons DM, Swanson LW, Arriza JL (1989) A complete protocol for in situ hybridization of messenger RNAs in brain and other tissues with radiolabeled single-stranded RNA probes. J Histotechnol 12:169-181.

Spencer SJ, Buller KM, Day TA (2005) Medial prefrontal cortex control of the paraventricular hypothalamic nucleus response to psychological stress: possible role of the bed nucleus of the stria terminalis. J Comp Neurol 481:363-376.

Swanson LW (1992) Brain maps: structure of the rat brain. New York: Elsevier.

Swanson LW, Cowan WM (1977) An autoradiographic study of the organization of the efferent connections of the hippocampal formation in the rat. J Comp Neurol 172:49-84.

Swanson LW, Köhler C (1986) Anatomical evidence for direct projections from the entorhinal area to the entire cortical mantle in the rat. J Neurosci 6:3010-3023.

Swanson LW, Kuypers HG (1980) The paraventricular nucleus of the hypothalamus: cytoarchitectonic subdivisions and organization of projections to the pituitary, dorsal vagal complex, and spinal cord as demonstrated by retrograde fluorescence double-labeling methods. J Comp Neurol 194:555-570.

Vertes RP (2004) Differential projections of the infralimbic and prelimbic cortex in the rat. Synapse 51:32-58.

Viau V, Sawchenko PE (2002) Hypophysiotropic neurons of the paraventricular nucleus respond in spatially, temporally, and phenotypically differentiated manners to acute vs. repeated restraint stress: rapid publication. J Comp Neurol 445:293-307.

Walaas I, Fonnum F (1980) Biochemical evidence for glutamate as a transmitter in hippocampal efferents to the basal forebrain and hypothalamus in the rat brain. Neuroscience 5:1691-1698.

Watanabe Y, Gould E, McEwen BS (1992) Stress induces atrophy of apical dendrites of hippocampal CA3 pyramidal neurons. Brain Res 588:341345.

Willner P (1997) Validity, reliability, and utility of chronic mild stress model of depression: a 10-year review and evaluation. Psychopharmacology 134:319-329. 